\title{
Nutrient Transport in the Mammary Gland: Calcium, Trace Minerals and Water Soluble Vitamins
}

\author{
Nicolas Montalbetti • Marianela G. Dalghi • \\ Christiane Albrecht $\cdot$ Matthias A. Hediger
}

Received: 11 September 2013 / Accepted: 22 January 2014 / Published online: 25 February 2014

(C) Springer Science+Business Media New York 2014

\begin{abstract}
Milk nutrients are secreted by epithelial cells in the alveoli of the mammary gland by several complex and highly coordinated systems. Many of these nutrients are transported from the blood to the milk via transcellular pathways that involve the concerted activity of transport proteins on the apical and basolateral membranes of mammary epithelial cells. In this review, we focus on transport mechanisms that contribute to the secretion of calcium, trace minerals and water soluble vitamins into milk with particular focus on the role of transporters of the SLC series as well as calcium transport proteins (ion channels and pumps). Numerous members of the SLC family are involved in the regulation of essential nutrients in the milk, such as the divalent metal transporter-1 (SLC11A2), ferroportin-1 (SLC40A1) and the copper transporter CTR1 (SLC31A1). A deeper understanding of the physiology and pathophysiology of these transporters will be of great value for drug discovery and treatment of breast diseases.
\end{abstract}

Keywords SLC transporters · ABC transporters · Calcium transporters and breast cancer

$\begin{array}{ll}\text { Abbreviations } \\ \text { ABC } & \text { ATP-binding cassette } \\ \text { BCRP } & \text { Breast cancer resistance protein } \\ \text { CP } & \text { Ceruloplasmin } \\ \text { CTR } & \text { Copper transporter } \\ \text { Dcytb } & \text { Duodenal cytochrome b } \\ \text { DMT1 } & \text { Divalent metal-ion transporter 1 } \\ \text { ER } & \text { Endoplasmic reticulum }\end{array}$

N. Montalbetti $(\bowtie) \cdot$ M. G. Dalghi $\cdot$ C. Albrecht $\cdot$

M. A. Hediger $(\square)$

Institute of Biochemistry and Molecular Medicine, and Swiss

National Centre of Competence in Research, NCCR TransCure,

University of Bern, Bühlstrasse 28, 3012 Bern, Switzerland

e-mail: montalbettin@gmail.com

e-mail: matthias.hediger@ibmm.unibe.ch

$\begin{array}{ll}\text { FPN } & \text { Ferroportin-1 } \\ \text { HEP } & \text { Hepcidin } \\ \text { IRE } & \text { Iron-responsive element } \\ \text { IRP } & \text { Iron-regulatory proteins } \\ \text { MECs } & \text { Mammary epithelial cells } \\ \text { MRP } & \text { Multidrug resistance associated protein } \\ \text { PCFT } & \text { Proton-coupled folate transporter } \\ \text { PMCA } & \text { Plasma membrane } \mathrm{Ca}^{2+} \text {-ATPase } \\ \text { RFC } & \text { Reduced folate carrier } \\ \text { RFVT } & \text { Riboflavin transporters } \\ \text { SERCA } & \text { Sarco(endo)plasmic reticulum } \mathrm{Ca}^{2+} \text { - ATPase } \\ \text { SLC } & \text { Solute carrier } \\ \text { SMCT } & \text { Sodium-coupled monocarboxylate } \\ & \text { cotransporters } \\ \text { SMVT } & \text { Sodium-coupled multivitamin transporter } \\ \text { SPCA } & \text { Secretory pathway Ca }{ }^{2+} \text {-ATPase } \\ \text { STEAP } & \text { Six-transmembrane epithelial antigen of the } \\ & \text { prostate } \\ \text { SVCT } & \text { Sodium-coupled vitamin C transporter } \\ \text { TfR } & \text { Transferrin receptor-1 } \\ \text { TRP } & \text { Transient receptor potential } \\ \text { ZIP } & \underline{\text { ZRT, IRT-like Protein }}\end{array}$

\section{Introduction}

The mammary gland is an exocrine organ which primary functions to produce milk to nourish young offspring. Milk is an emulsion of fat and an aqueous solution containing sugars, proteins, minerals and vitamins. The alveoli are the fundamental secretory units of the breast, composed of a single layer of polarized epithelial cells which are surrounded by contractile myoepithelial and adipose cells (Fig. 1). During lactation, milk is produced and secreted into a central lumen of the alveolus by a diverse set of transport mechanisms that 
occur both within and between alveolar epithelial cells (Fig. 1). The alveoli are organized into lobules, each of which drains into a ductal system which finally carries the secretion products to the outside.

\section{Epithelial Transport in the Mammary Gland}

The composition of the milk reflects the orchestration of many transport processes found in mammary epithelial

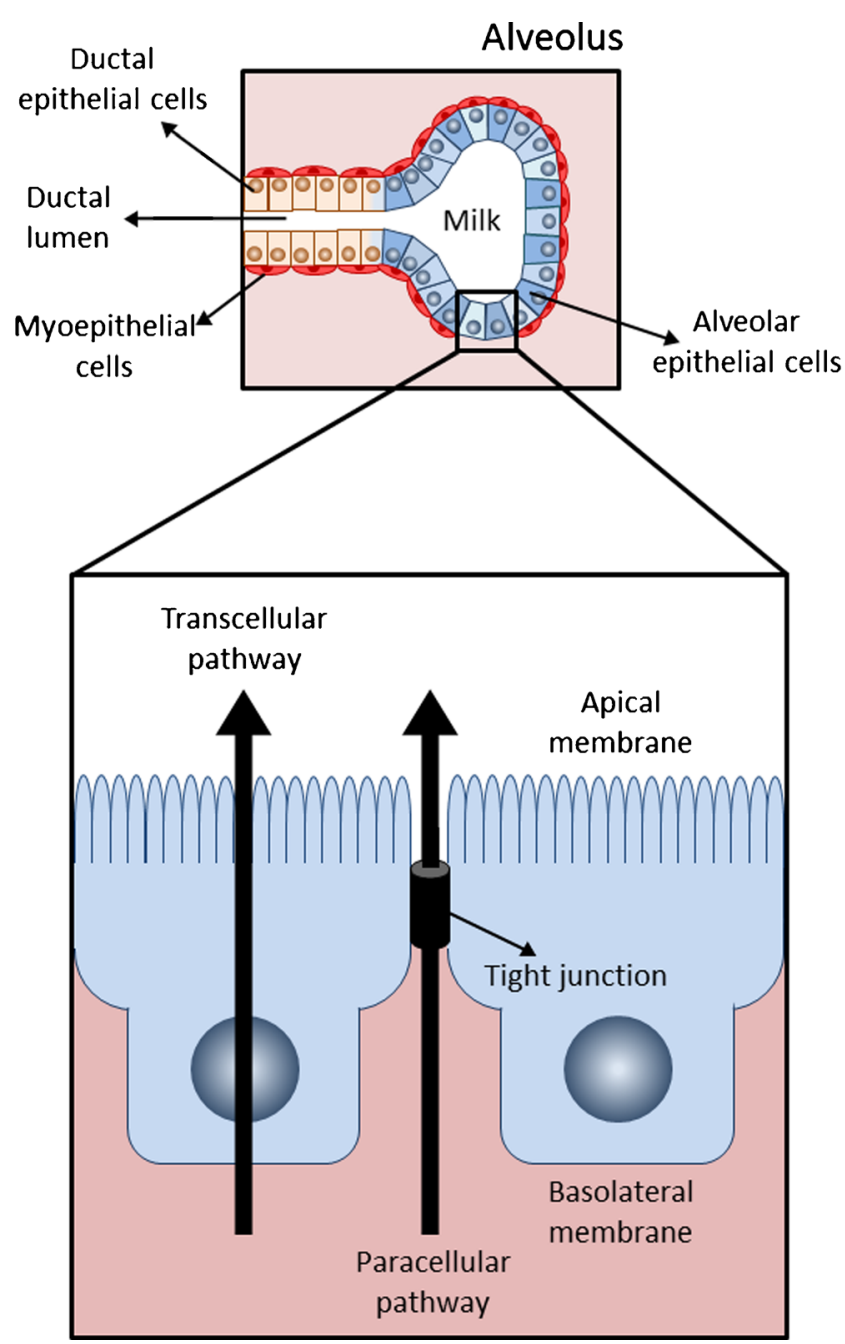

Fig. 1 Schematic representation of an alveolus. The alveolus is the fundamental secretory unit of breast tissue. Alveoli consist of a single layer of polarized secretory epithelial cells (alveolar cells) surrounded by contractile myoepithelial and adipose cells (not shown). The alveolar cells are joined together by tight junctions. These polarized cells and the tight junctions allow mammary epithelium to perform vectorial transport of electrolytes and non-electrolytes into the milk. Two major pathways are followed by solutes when moving across an epithelium, the paracellular and the transcellular pathways. Paracellular pathway: the substances are transported across an epithelium by passing through the tight junctions and the lateral intercellular spaces surrounding each epithelial cell. Transcellular pathway: substances are transported through the cell, passing through both the apical membrane and basolateral membrane cells (MECs). Hence, understanding the mechanism underlying mammary epithelial solute transport is essential to understand the cell biology and physiology of milk formation. To achieve transepithelial vectorial transport of the milk components, MECs take advantage of their asymmetrical properties (i.e. different but complementary transport proteins are expressed in the apical and basolateral membranes). These polarized cells are joined together by tight junctions that also act as a barrier "fence" which helps maintain epithelium polarity. These two functional structures (polarized cells and tight junctions) provide mammary epithelium asymmetry and as a consequence the capability of vectorial transport of solutes.

There are two principle pathways by which solutes can move across an epithelium, the paracellular and the transcellular pathways. In the first pathway, the substances are transported across the epithelium by passing through the tight junction and the lateral intercellular spaces surrounding each epithelial cell. In contrast, the transcellular pathway involves the transport of substances through the cell, passing through the apical and basolateral membranes. Epithelia were divided by Frömter and Diamond into two broad categories based on the relative resistance of tight junction [1]. Leaky epithelia have low resistance tight junctions (from 6 to $150 \Omega \mathrm{cm}^{2}$ ), whereas tight epithelia show high resistance tight junctions (from 500 to $70,000 \Omega \mathrm{cm}^{2}$ ). The junctional resistance has also consequences for other physiological properties of epithelia. Tight epithelia can establish and maintain large electrolyte and non-electrolyte gradients and they can generate high transepithelial voltages. In contrast, leaky epithelia show lower transepithelial voltage and they cannot maintain large solute concentration gradients. In general, leaky epithelia are very efficient in performing bulk transepithelial transport of solutes and water in a nearly isosmotic fashion. On the other hand, tight epithelia can generate and maintain large transepithelial ion concentration or osmotic gradients.

Lactogenesis comprises profound and rapid programmed changes that transform the alveolar epithelium into a fully secretory active tissue at parturition. The mammary epithelium is leaky before lactation, allowing the passage of substances between epithelial cells. Shortly after parturition and throughout lactation, there is a dramatic increase in milk secretion in responses to a complex sequence of hormonal stimuli. Tight junctions form a highly impermeable barrier between the milk and interstitial fluid. During this phase, the alveolar epithelium shows the characteristics of a tight epithelium that allows the establishment and maintenance of a large transepithelial concentration gradient for ions and macromolecules. Moreover, the permeability of tight junctions is closely 
related to milk secretion. A decrease in tight junction permeability is accompanied by an increase in the rate of milk secretion and conversely, an increase in tight junction permeability is accompanied by decrease in the milk secretion rate. The roles of the epithelial tight junction and the paracellular pathway in milk production are, however, beyond the scope of this review. A review on tight junction function in the mammary gland can be found in the present issue by Stelwagen and Singh as well as in previous contributions to this journal $[2,3]$.

\section{The Transcellular Pathway in the Alveolar Epithelium}

During lactation, the transcellular pathway is the main route for transporting the milk nutrients, such as calcium, iron and water soluble vitamins. This assumption is based on the low permeability of the tight junction of alveolar epithelia during lactation and the large concentration gradients of ions and macromolecules existing between blood and milk. Four major cellular routes are thought to be utilized by the mammary epithelium to secrete the milk components:

1- Exocytotic pathway. Milk proteins synthesized in the endoplasmic reticulum (ER), such as casein, are packaged into Golgi-derived vesicles. Here alveolar cells add different nutrients, as calcium (see Calcium transport section below), zinc, phosphate, lactose and citrate to the lumen of the secretory vesicles. These secretory vesicles move to the apical membrane where they secrete their content into the milk space by exocytosis.

2- Lipid pathway. Lipids coalesce into cytoplasmic lipid droplets and move to the apical membrane. These lipid droplets are enveloped by the apical plasma membrane and finally secreted from the cell as the milk fat globule.

3- Transcytosis pathway. The basolateral membrane takes up proteins, such as immunoglobulins, by endocytosis. These vesicles are transported across the cell to the apical membrane where the cell secretes their contents into the milk space by exocytosis.

4- Membrane transport pathways. Specific transporters located at the basolateral membrane, Golgi apparatus, secretory vesicles and apical membrane move electrolytes and nonelectrolytes from the interstitial fluid into the milk.

These cellular pathways were described in detail by McManaman and Neville [4], and are also addressed in several reviews of this issue (e.g. Ontsouka et al.).

\section{Membrane Transport Pathways}

In the following sections we discuss the transport mechanisms involved in secretion of calcium and micronutrients, such as iron, cooper and water soluble vitamins, into milk. In this review we focus on the membrane transporters expressed at the apical or basolateral membranes of MECs (i.e. transcellular pathway) that may play a role in the delivery of essential nutrients into the milk. Members of the SLC30 (zinc efflux transporters) and SLC39 (zinc influx transporters) families have been shown to be involved in the vectorial transport of zinc trough the mammary secretory epithelium. The role of these transporters in the regulation of milk zinc concentration are not going to be covered here since they are reviewed by McCormick et al. in this review series.

\section{Calcium Transport in the Mammary Gland}

Milk production requires the transport of large amounts of calcium through the MECs. Human milk contains up to $5 \mathrm{mM}$ of total calcium after $90 \mathrm{~h}$ post-partum [5]. Mammary gland calcium transport comprises a transcellular and overall unidirectional flux [6] against the steep concentration gradient that exists between the extracellular fluid and the milk operating over an extended period of time (Fig. 2). This process mainly involves (i) the uptake of calcium from the interstitial fluid through the basolateral membrane of the MEC, (ii) its secretion to the milk from the apical side, and (iii) the intraorganelle storage and buffering of cytoplasmic calcium during its passage through the cell in order to avoid its cytotoxicity. Figure 2 shows a representation of the different transport mechanisms that regulate the concentration of calcium in the milk.

Role of TRP Channels in Calcium Secretion The first event, i.e. the calcium transport across the blood-facing membrane, must operate with high capacity, given the large amount of calcium secreted into milk. Experimental findings showed that this process is temperature dependent and induced during the transition from pregnancy to lactation [7]. Calcium channels (e.g. members of the transient receptor potential (TRP) family) have been proposed to play a role in this process since their kinetic characteristics make them likely candidates to contribute to transepithelial calcium transport. However, the exact mechanism responsible for calcium transport across the basolateral membrane of secretory MECs still remains largely unknown [8]. Although some calcium channels have been involved in mammary gland pathologies such as breast cancer [9-11], the identification of the molecular entity(ies) involved in calcium secretion to the milk is still missing. One class of calcium channels compatible with the characteristics of the calcium transport observed in MECs are the TRP superfamily of cation channels, in particular TRPV5 and TRPV6. These channels present high selectivity for calcium over monovalent cations and display constitutive activity and saturable kinetics in the submillimolar range [12, 13]. TRPV 5 has been found to be localized in apical membranes in the kidney $[14,15]$ but not in the mammary gland, whereas TRPV6 is found in the apical membranes of 
a
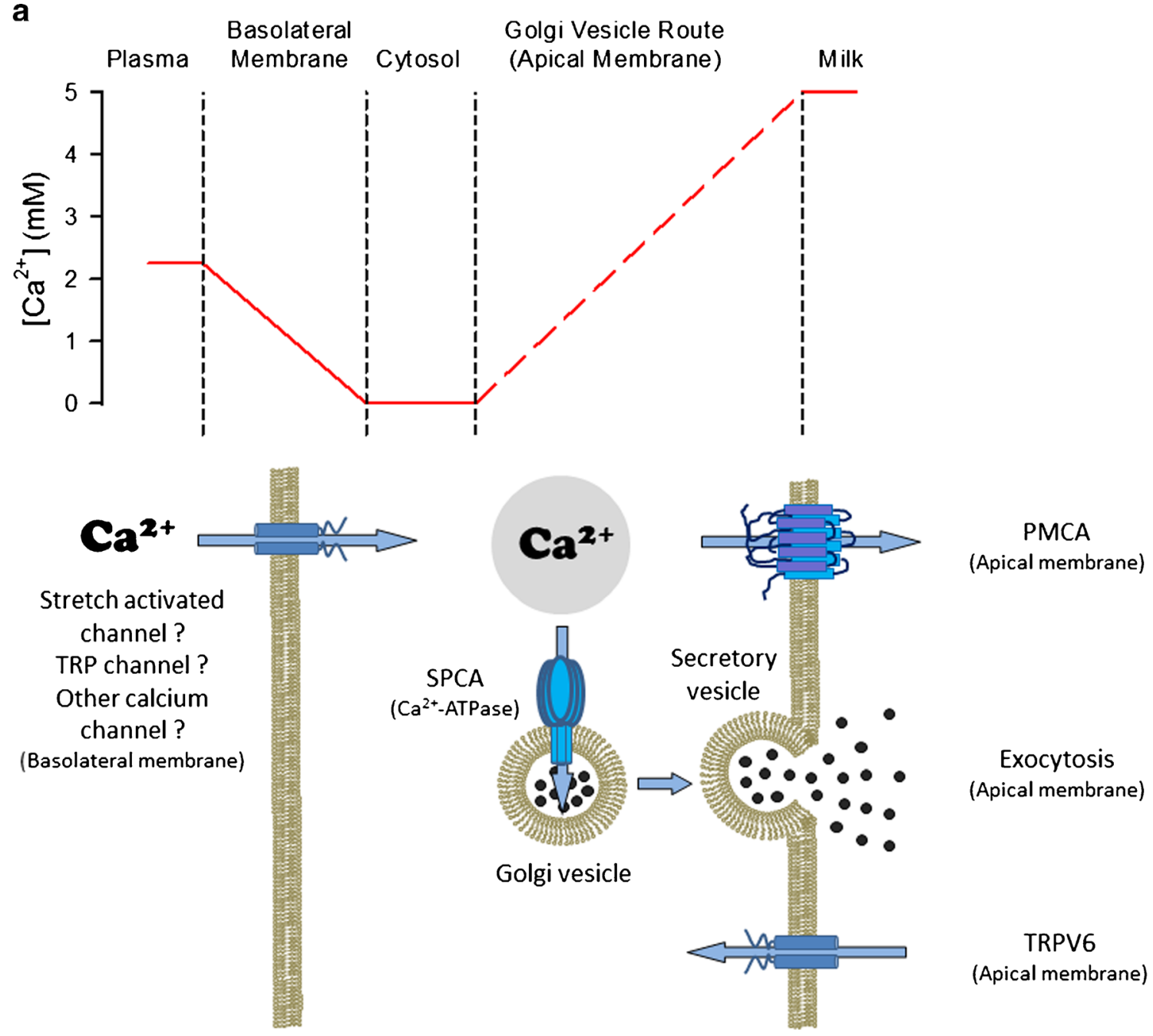

b

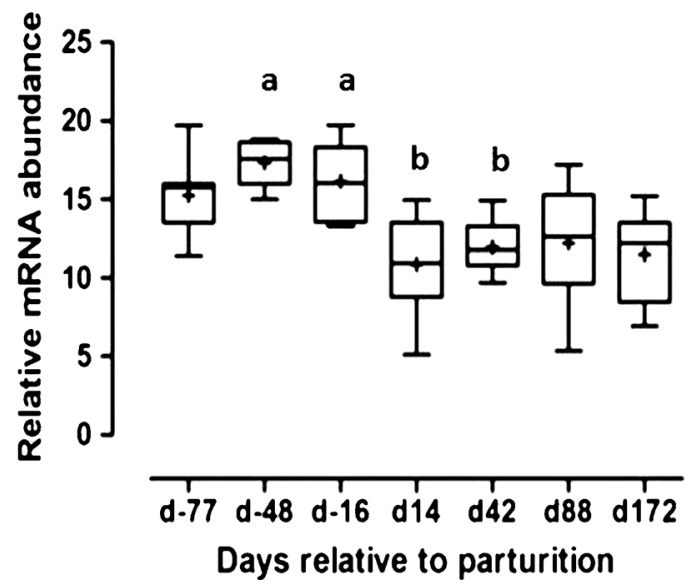

epithelial cells of the intestine and exocrine tissues [16]. Indeed, apical expression of TRPV6 has been shown in normal human MEC [16] where it would mediate calcium re-uptake from the luminal side.
Differential Expression of TRPV-6 During Pregnancy Lactation Cycle Given its apical localization, TRPV6 would be expected to contribute to the re-uptake of calcium from the milk rather than to the transport of calcium into the milk. Recent 
4 Fig. 2 Transcellular transport of calcium into the milk. a In the upper panel, the calcium concentration gradients across the different cellular membranes are represented with a red line. Since the calcium concentration in the Golgi vesicles remains unknown, the gradient of calcium between the cytosol and the milk across the apical membrane is represented by a dashed line. The transport mechanisms that mediate basolateral calcium uptake are not known. Calcium transport down its electrochemical gradient across the basolateral membrane may be mediated by a passive transport mechanism (e.g. calcium channels). Calcium secretion to the milk is traditionally accepted to occur via exocytosis of secretory vesicles packaged within the Golgi as calcium phosphate, calcium citrate and calcium complexed with caseins, the latter comprising the majority of the total calcium present in the milk. Once inside the alveolar cell, calcium is pumped across Golgi vesicles by SPCA, across the endoplasmic reticulum by SERCA (not shown), or is sequestered by cytosolic calcium-binding proteins. Finally, calcium is secreted into milk by exocytosis of the Golgi-derived vesicles at the apical membrane. Alternatively, calcium can be pumped out of the cell into the milk by PMCA2bw. The apical membrane does not display a high permeability for calcium. TRPV6 has been shown to be expressed in the apical membrane of human MECs, however its role in mammary epithelial calcium transport remains largely unknown. b TRPV6 mRNA expression during the pregnancy-lactation cycle. TRPV6 mRNA abundance was measured in bovine mammary gland biopsies repeatedly collected at different stages of the pregnancy lactation cycle (for details see $[172,173]$ ). The mRNA expression of TRPV6 was normalized to the mean of the two housekeepers ubiquitin and cyclophilin. Data are presented as mean \pm SD. Statistical analysis was performed using Kruskal-Wallis ANOVA followed by Dunn's Multiple Comparison Test. Day -48 and -16 : dry period, non-lactating state; day $14,42,88,172,-77$ : early, mid and late lactation

studies in our laboratories revealed significant downregulation of bovine TRPV6 during lactation (Fig. 2b; unpublished data obtained in collaboration with K. Sejrsen, Aarhus University, Denmark). Figure $2 \mathrm{~b}$ shows that the mRNA abundance of bovine TRPV6 is greatest during the periods of reduced or absent lactation, i.e. at the end of the previous lactation (d-77) and during the dry period (d-48 and d-16) preceding the next lactation cycle. In contrast, the gene expression of TRPV6 was lowest during the first 2 weeks after parturition when the milk yield starts to markedly increase in early lactation (d14 to 100). The gene expression of TRPV6 remained unchanged throughout early and mid-lactation (d100 to 200). The significantly higher TRPV6 mRNA levels during the non-lactating states as compared to lactation suggest a physiological mechanism particularly during the non-lactating states (i.e. before milk production or during weaning) to prevent loss of excessive serum calcium into the mammary alveoli through reabsorption via TRPV6. On the other side, low TRPV6 levels during lactation may prevent reabsorption of calcium from the milk in the lactating state when the calcium demand for the neonate is high. In general, the apical localization of TRVP6, if consistently confirmed, could suggest that the transporter might play a role in calcium re-uptake from the alveolar lumen. The process of calcium re-uptake during lactation might contribute to maintain the necessary elevated milk calcium content necessary for fulfilling nutritional requirements of the offspring. On the other hand, the re-uptake of calcium through TRPV6 might also play an important role especially during involution when milk production ceased and the synthetic activity of the mammary gland is low. Indeed, in non-lactating mammary tissues, it could be assumed that calcium re-uptake contributes to reduce its luminal content, and, therefore, the risk of calcification in the mammary gland. This mechanism may play a role in the prevention of breast lesions. However, additional investigations are needed to better understand the underlying pathways, including hormonal influences and regulatory factors, leading to the differential expression profile, and to clearly define the physiological role of TRPV6 in the lactating and non-lactating mammary gland.

Role of Stretch-Activated Calcium Channels Channel candidates for calcium entry at the basolateral membrane are the stretch-activated channels as MECs undergo extensive mechanical deformation upon filling and emptying of the alveoli. Experimental evidence showed that hypo-osmotic stress generates an increase in the cytosolic calcium concentration in lactating MECs, being the major contributor to the signal for influx of extracellular calcium [17]. However, no molecular entity has yet been found to be responsible for the observed effect. Moreover, the mechanical effect seems to be more complex than the simple direct activation of stretch-sensitive channels, as demonstrated by Enomoto el al. [18]. These investigators found not only that the mechanically stimulated cultured mouse mammary cells showed an increase in the intracellular calcium concentration but the response was also extended to the non-touched surrounding cells, suggesting the involvement of a paracrine factor [19, 20]. Along this line of evidence, ATP is likely to be the mediator, as it has been found to be released upon mechanical stimuli in cultured mammary cells [20] and to trigger the influx of calcium from the extracellular side by activating the P2-purinergic receptors [21]. However, in spite of all the experimental efforts made in this field, as also shown by the genome-wide screen performed by VanHouten \& Wysolmerski [22], the identity of the putative calcium channel responsible for calcium entry into MECs remains elusive. Additionally, although the presence of P2purinergic receptors is well documented in breast cancer cell lines [23], experimental data failed to show its presence in preparations of primary acini in suspension freshly isolated from mouse [17]. This can be explained by the fact that the phenotype of a tumour cell line can differ considerably from that of primary cells and, thus, the experimental model would not reflect precisely what occurs in the physiology of normal cells.

Exocytotic Pathway for Calcium Secretion Once in the MEC, calcium secretion to the milk is traditionally accepted to occur via exocytosis of secretory vesicles packaged within the Golgi 
[6] as calcium phosphate, calcium citrate and calcium complexed with caseins, the latter comprising the majority of the total calcium present in the milk [24]. The transporters likely to be responsible for calcium accumulation in the Golgi reticulum are the newly discovered secretory pathway $\mathrm{Ca}^{2+}$ ATPases (SPCAs; [25, 26]). Two SPCA isoforms, termed SPCA1 and SPCA2, have been reported to exist in humans and also to be localized in the Golgi complexes [27-29]. SPCA1 is ubiquitously expressed, including its presence in the mammary gland [27], and is thought to represent a housekeeping form of the pump important for calcium homeostasis in the lumen of the Golgi. SPCA2 has a more restricted tissue distribution and the mammary gland is one of the tissues where it is predominately found [28]. Our knowledge about the exact role of SPCAs in the mammary gland is still limited. Experimental evidence supports the idea that regulation of SPCA2 is related to milk production and/or secretion as it has been observed that mRNA levels of SPCA2 increase 35fold (at day 1 of lactation) compared to nulliparous mice [30]. In contrast, SPCA1 displays a modest increase in its expression being $\sim 1.5$-fold at day 10 during pregnancy and $\sim 2$-fold at day 1 of lactation in mice [30] and up to 6-fold in lactating rat mammary gland [31]. Besides calcium transport, SPCAs can also pump $\mathrm{Mn}^{2+}$ to the luminal Golgi. Both cations are required for activation of intraluminal enzymes needed for protein and carbohydrate modifications. As an example, $\mathrm{Ca}^{2+}$ and $\mathrm{Mn}^{2+}$ stimulate casein phosphorylation by modulating casein kinase activity, $\mathrm{Mn}^{2+}$ being more effective than $\mathrm{Ca}^{2+}$ [32]. Casein phosphorylation and its interaction with calcium phosphate are important factors that determine the normal casein micellar structure secreted by the mammary gland $[32,33]$. Calcium accumulation in the Golgi would then be necessary not only for milk enrichment but also for the organelle's normal function [34] and could also contribute to the maintenance of the cytosolic calcium levels low in order to prevent calcium cytotoxicity.

Role of Calcium Pumps In addition to SPCAs, calcium uptake into Golgi has also been attributed to sarco(endo)plasmic reticulum $\mathrm{Ca}^{2+}$ - ATPases (SERCAs) that are not restricted to the ER and to plasma membrane $\mathrm{Ca}^{2+}$-ATPases (PMCAs) in transit to the plasma membrane [35]. SERCAs involvement in the mammary gland during lactation seems to be also related to the synthesis of new secretory proteins in the ER, mainly the caseins, but not to the extent or rate of their secretion [32]. PMCAs, however, play a more significant role in terms of calcium secretion than SERCAs. In fact PMCA2 plays a major role in calcium secretion (Fig. 2), since null mutations in PMCA2 of lactating mice lead to a significant decrease $(\sim 60-70 \%)$ in the calcium content in the milk $[22,36]$. Among the human PMCAs isoforms (PMCA1-4), isoform 2 is the one that displays the highest basal activity levels and the greatest affinity for calmodulin, which is one of the main activators of the pump [37]. Due to its localization at the apical membrane [22], PMCA2 transports calcium directly into milk, independently of its putative contribution to the Golgi accumulation. Interestingly, during lactation total PMCA protein expression is up-regulated in rat whole mammary gland due to an increase predominantly in the PMCA2bw splice variant, which remains elevated at levels that are almost 100-fold higher compared to levels during pregnancy $[31,38]$.

These data suggest a role for PMCA2 beyond the fine tuning of calcium signals and the maintenance of low resting cytosolic calcium concentrations traditionally attributed to all PMCAs [39]. Interestingly, PMCA2 has been found in secreted milk particularly concentrated in milk fat globule membranes derived from the apical membrane of MECs [31]. This observation would explain the high expression of PMCA2 mRNA found in the mammary gland as a mechanism to rapidly replace PMCA2 lost to milk secretion. In addition, PMCA2 may also contribute to calcium accumulation in the Golgi complex during its transit to the plasma membrane, and as a consequence a further contribution to calcium secretion into milk. However, PMCA2 could not been found in Golgi or secretory vesicle membranes in immunoelectron micrographs [22], indicating that PMCA2 in transit to the apical membrane would not be a significant source of Golgi $\mathrm{Ca}^{2+}$-ATPase activity.

Intracellular Calcium Buffers While transporting high fluxes of calcium during lactation, MECs also maintain cytosolic calcium levels low as calcium also acts as a second messenger able to trigger a plethora of cell responses including cell death and apoptosis [40]. In this regard, intracellular calcium buffers, either cytosolic or intraorganelle, play a major role [41, 42], and in some cases they also participate, although in an indirect way, in the transepithelial transport process. For example, calreticulin is a major calcium binding protein found in the ER [43] that has been reported to be upregulated in the rat mammary gland during lactation increasing the calcium accumulation capacity of the ER needed for milk production. Another intraorganelle calcium buffer is nucleobindin, which is located in the Golgi apparatus and facilitates the storage of calcium in its lumen $[44,45]$. It has been observed that overexpression of SPCA1 increases nucleobindin expression in COS-7 cells [36]. Thus, increasing the expression of intraorganelle calcium buffer proteins assist both maintaining low cytosolic calcium concentrations and in calcium uptake into the vesicles prior to the release of their content at the apical surface.

In summary, calcium secretion into the milk is the result of the concerted mechanisms of its uptake into the MEC from the blood side and its export through the apical side of the MEC. Although there is substantial evidence for the involvement of different channels and pumps in calcium enrichment of the 
milk during lactation, more experimental efforts are required to elucidate the exact molecular events. Currently, the identity of the calcium channel that mediates transport of calcium across the basolateral membrane of the MEC is unknown. Moreover, there is no consensus on the mechanism responsible for its secretion into the alveolar lumen: one model proposes that most or all of the calcium in the milk is likely derived from exocytotic secretory vesicles from the Golgi compartment while another model claims that the active apical transport mediated by $\mathrm{Ca}^{2+}$-ATPases (PMCAs) is of central importance. These two mechanisms may not be mutually exclusive, and the contribution of each of them to calcium secretion needs to be carefully examined.

Role of Calcium Transporters in Breast Cancer Intracellular $\mathrm{Ca}^{2+}$ signaling is a key regulator of proliferation, cell cycle progression and apoptosis. There is increasing evidence that PMCA alterations together with an increase in $\mathrm{Ca}^{2+}$ influx mediated by some members of the TRP family of calcium channels are associated with the development and/or progression of breast tumors [16, 46-48]. The up-regulation of PMCA2 and the down-regulation of PMCA4 observed in the rat mammary gland during lactation appears to be involved in regulating differentiation and proliferation processes in this tissue [38]. Mammary gland involution upon weaning is triggered by milk stasis [49] which is associated with PMCA2 down-regulation. By decreasing PMCA2 expression, the alveoli undergo a sustained increase in intracellular calcium levels and as a consequence apoptosis [50], thus providing a mechanism of coupling the secretory process of lactation with the cell death machinery required for involution. Pathophysiological PMCA2 activity may lead to mammary gland tumorigenesis and protection of breast cancer cells by preventing them from apoptosis. This may explain why elevated PMCA2 expression is associated with larger tumors, higher grade and nodal metastases, and prediction of poor outcome in breast cancer patients [50].

Overexpression of TRPV 6 has been furthermore associated with breast cancer and mammary cell proliferation. TRPV6 is up-regulated in breast cancer tissue compared with normal mammary tissue, both at the protein [16] and mRNA [46] level. An increase in the transcription of TRPV6 up to $69 \%$ was observed when T47D breast cancer cells were treated with estrogen and progesterone. [46]. Moreover, blocking the estrogen receptor with tamoxifen caused a reduction of TRPV6 transcript levels. Interestingly, tamoxifen not only down-regulated TRPV6 mRNA expression, but also directly inhibited TRPV6 calcium channel activity with an $\mathrm{IC}_{50}$ value of $7.5 \mu \mathrm{M}$ [46]. Based on to these results, it was suggested that the inhibition of TRPV6 accounts, at least in part, for the antiproliferative activity of the widely used breast cancer drug treatment tamoxifen. In T47D cells, TRPV6 silencing reduced the proliferation rate by $60 \%$ with a concomitant reduction of calcium transport by $50 \%$ [46]. In agreement, recent studies have shown that higher levels of TRPV6 are correlated with more invasive breast cancers [48] and that breast cancer patients with high TRPV6 levels have decreased survival rate compared with patients to low or intermediate TRPV6 expression [51]. Specific TRPV6 inhibitors might be clinically useful for the treatment of estrogen receptor-negative breast cancers.

Although the observations on PMCA2 and TRPV6 seem to conflict each other, as in both cases the resulting phenotype (up-regulation of a calcium pump or up-regulation of a calcium channel) appears to provide an advantage in survival to the cancer cell, it may be possible that in the first case the higher calcium efflux confers cell resistance to apoptosis while in the second case, the higher calcium influx provides an augmented response to proliferative signals. Thus, further studies on the role of calcium transport pathways in breast cancer development and progression are needed.

\section{Trace Element Transport into Milk}

Adequate supply of trace elements, such as zinc, copper and iron, from breast milk is essential for optimal neonatal growth and development. The concentration of these trace elements in breast milk is tightly regulated and maintained by MECs during lactation. This regulatory activity is particularly notable in two different aspects:

1. The concentration of trace elements in breast milk are remarkably stable at each of the different stages of lactation [52]. Independent of the absolute values, the concentrations of iron [53-55], copper [55, 56] and zinc [55, 57] in human milk are highest during the first few days after birth and subsequently decrease as lactation progresses.

2. Milk levels of these trace elements are independent of maternal mineral status $[58,59]$. There is no significant correlation between maternal intake of cooper, iron, and zinc and the corresponding trace element levels in human milk $[54,60]$.

The current experimental evidence suggests that the secretion of iron, zinc, and copper into milk is therefore tightly regulated by MECs. Despite their importance regarding the nutritional aspects of milk, there is only scarce information available about the molecular and cellular mechanisms regulating trace element concentrations in the milk.

\section{Iron Transport in the Mammary Gland}

The concentration of iron in breast milk is relatively low compared to the calculated requirements for the growing 
infant. Due to extensive iron stores present at birth full term infants only become vulnerable to iron deficiency after about 6 months of age [61, 62]. Nonetheless, the mammary gland has a remarkable capacity for controlling breast milk iron levels within a narrow concentration range. Moreover, iron bioavailability in human milk is higher than in cow's and formulas [63], suggesting that breast milk supply is important to meet the iron needs of breast-fed infants. Importantly, maintaining breast feeding for at least 6 months has been recommended to prevent iron deficiency in infants $[61,62]$. Therefore, understanding the transport mechanisms involved in iron secretion into milk is important to understand the role of this trace mineral in infant nutrition.

Epithelial Iron Uptake Pathway Cellular iron uptake is a complex process that is coordinately regulated by several proteins, such as transferrin, transferrin receptor and divalent metal transporter-1 (DMT1; SLC11A2). Most cellular iron is acquired from holotransferrin (i.e. diferric transferrin). Iron in serum is chelated by transferrin and transported to the different tissues for utilization and storage. At the extracellular fluid $\mathrm{pH}$, holotransferrin binds with high affinity to a transferrin receptor-1 (TfR) in the plasma membrane causing its internalization. After endocytosis, the endosome is acidified causing the dissociation of iron from transferrin-TfR complex. The apotransferrin-TfR complex is recycled to the cell surface, where it is again exposed to the extracellular fluid. The physiological extracellular $\mathrm{pH}$ prompts the dissociation of transferrin from its receptor.

Ferric iron released from the transferrin-receptor complex into the endosomes is reduced to the ferrous form by members of the six-transmembrane epithelial antigen of the prostate (STEAP) family [64-66]. Iron is subsequently transported out of the endosome to the cytosol by DMT1 [67-70]. This transporter uses the $\mathrm{H}^{+}$electrochemical gradient as the driving force to transport a rather broad range of divalent metal ions, such as $\mathrm{Fe}^{2+}, \mathrm{Mn}^{2+}$ and $\mathrm{Zn}^{2+}[71,72]$. In addition to DMT1, other transporters and ion channels, such as zinc transporters of the SLC39A family [73-75] and calcium ion channels [76-78] have been shown to mediate iron uptake. However their physiological role remains largely unknown. Once in the cytosol most intracellular iron binds to ferritin, the major storage form of iron. A small pool of soluble iron is maintained as a component of many cellular functions, such as energy transduction by mitochondrial cytochromes.

Iron is transferred from rat plasma to milk in a rapid process that does not involve cellular iron pools [79, 80]. Iron uptake by the MECs is mediated by TfR and it has been proposed to be the initial rate-limiting step in the transfer of iron into milk [81]. TfR-mediated iron uptake in MECs has been described in rabbit [82], rat [83, 84] and mouse [81, 85]. However the role of TfR in iron transport in the lactating mammary epithelium remains unclear. In contrast to milk iron levels that have been shown to decrease during lactation, a significant increase in TfR occurs during mammary growth and the TfR level remains high during lactation in rat $[84,86]$ and mouse [85]. It was suggested that the control of milk iron concentration occurs following iron uptake into the mammary gland [87].

The transport of iron into the cytosol of MECs is mediated by DMT1. This transporter has been shown to be present in the intracellular compartment of secretory epithelial cells lining the alveolar lumen in rat mammary gland [88]. Interestingly, in rat mammary, gland DMT1 levels were shown to decrease throughout lactation with the highest levels observed in early lactation [88, 89]. This decrease in DMT1 expression correlates with the normal decline in milk iron during lactation in rats [88]. In the same study, no significant differences in DMT1 expression levels in the mammary gland and milk iron levels were observed when comparing rats fed a normal diet with those fed a low-iron diet [88]. These results suggest that DMT1 expression in the mammary gland as well as milk iron levels are independent of the dietary iron intake. Moreover, low iron intake resulted in decreased mammary gland iron content, suggesting that DMT1 expression in the mammary gland is not regulated by intracellular iron levels as it was observed in small intestine [71]. Alternative splicing between two $5^{\prime}$ and two $3^{\prime}$ exons result in four DMT1 isoforms [90] that differ in their tissue distribution and regulation. Only two of them are regulated by iron on the post-transcriptional level by the iron responsive element (IRE)/iron regulatory protein (IRP) system (see [91] for review). The decline of DMT1 expression with an unchanged mammary gland iron concentration throughout lactation [88] suggests that the IRE/ IRP system may not play a key role in regulating the normal decline of DMT1.

The effect of a marginal vitamin A diet in rats added another layer of complexity to the regulation of iron secretion into milk. Marginal vitamin A deficiency reduced milk and mammary gland iron levels which was correlated with a decreased TfR and DMT1 expression despite having little effect on maternal iron status [92]. However, it is unclear whether vitamin A has a direct effect on TfR and DMT1 expression resulting in a reduction of iron levels in the milk. Interestingly, reduced milk iron concentration due to marginal maternal vitamin A intake in rats resulted in severe iron deficiency anaemia in the suckling neonate [92]. Pregnant and lactating woman are especially vulnerable to iron deficiency anemia caused by vitamin A deficiency. Maternal anemia adversely affects the iron status including iron stores of the newborns $[93,94]$, increasing the risk for iron deficiency, if iron intake is inadequate. Iron milk levels may be particularly important to meet the iron needs of neonates with decreased iron stores.

Iron Transport Within the Cell The vectorial transepithelial transport of iron requires its intracellular translocation across 
the cytosol of the epithelial cell. Low molecular weight chelates or chaperone proteins were suggested to regulate the transport of iron within the cell. Paraferrin, a largemolecular-weight protein complex, has been postulated to shuttle iron within human and rat enterocytes [95]. The poly r C-binding protein (PCBP) 1 acts as a cytosolic iron chaperone that facilitates the loading of iron into ferritin [96]. However, the molecular mechanisms involved in iron transfer from apical to basolateral membranes within epithelial cells, such as MECs, remains largely unknown.

Epithelial Iron Efflux Pathway Ferroportin-1 (FPN, also known as Ireg 1 or MTP1), the product of the $S L C 40 A 1$ gene, is the only known mechanism that mediates the transport of iron out of the cell and it appears to be present in almost all cell types. It is expressed at particularly high levels in several tissues and cells that play critical roles in body iron homeostasis including duodenal enterocytes, placenta syncytiotrophoblasts, hepatocytes and reticuloendothelial macrophages. The localization of FPN in cells and tissues is consistent with its proposed function of exporting iron from cells. The duodenal expression of FPN is limited to the basolateral membrane of enterocytes, particularly at the tip of the villous rather than the crypt [97-99]. FPN is also expressed at the basal surface of placental syncytiotrophoblasts, where the protein is thought to be involved in iron transfer between the maternal and fetal circulation [98]. FPN is highly expressed in macrophages, particularly those residents in the red pulp of the spleen, bone marrow, and the Kupffer cells of the liver. In these cells, iron released during the degradation of damaged or senescent erythrocytes is transported out of the cell by FPN. This erythroid/ marcrophage recycling system is responsible for approximately $80 \%$ of daily iron traffic in the body.

The cellular iron efflux transporter FPN has been shown to be expressed in human [100] and rat mammary gland [88]. Within rat MECs, FPN has been shown to be localized at both intracellular- and membrane-associated compartments [92]. According to its intracellular localization in rat MEC, it was suggested that FPN may be involved in the transport of iron into the Golgi and secretory vesicles [88]. This model proposes that iron is concentrated in the Golgi and secretory vesicles and secreted by exocytosis. MECs seem to have an efficient mechanism for transporting iron into vesicles of the ER-Golgi secretory pathway. Iron is present in the lipid fraction of the milk complexed with the enzyme xanthine oxidase as well as in the aqueous fraction mainly associated with milk proteins, such as casein and lactoferrin $[63,101]$. Similarly to MECs, FPN is predominantly localized to a cytoplasmic compartment in reticuloendothelial system cells [97, 102, 103], were it was proposed to mediate iron transport from the cytosol to an intracellular vesicular compartment [97, 103]. Although the role of FPN in the transport of iron across the plasma membrane is well established, its role in iron trafficking between the cytosol and organelles remains speculative. FPN localized at the plasma membrane may also mediate a direct secretion of iron into the milk across the apical membrane. Direct iron export by FPN through the plasma membrane of macrophages has also been suggested [102]. Confocal fluorescent analysis revealed the presence of FPN microdomains at the plasma membrane of bone marrow derived macrophages, suggesting a vesicular trafficking of the protein between the cytosol and cell surface [103]. Alternatively to its putative role as an intravesicular iron "concentrator", FPN expressed at the intracellular vesicular compartment may be recruited to the membrane when needed for iron export.

The regulation of FPN expression seems to be a complex process that may involve several different regulatory mechanisms in a tissue-specific manner. Originally, FPN expression in murine liver and duodenum was shown to be regulated by iron in a reciprocal manner [97]. In Kupffer cells of the liver, FPN protein levels correlate directly with iron levels [97]. This pattern of regulation has also been shown in HepG2 cells [104] and macrophages [105, 106]. In contrast, duodenal epithelial cells show a strong FPN immunohistochemical staining in iron-deprived mice and weaker staining in ironrepleted mice [97]. Duodenal FPN expression has also been shown to be upregulated by iron deficiency or downregulated by iron excess in humans [107], mice [99] and rats [108]. In mouse placental syncytiotrophoblasts no changes in the expression of FPN were observed after iron depletion [109]. Although iron concentration remains unchanged throughout lactation in rat mammary gland, FPN expression is higher during early lactation and decreases throughout lactation [88]. The regulation of FPN expression by iron is currently poorly understood. FPN transcripts containing IRE and non-IRE have been reported. An mRNA encoding FPN that contains IRE in the $5^{\prime}$ UTR [97] could be regulated by iron at the post-transcriptional level by the IRE/IRP system. FPN transcripts that are not subject to repression by the IRE/IRP system in iron-deficient conditions have been described in duodenal enterocytes and in erythroid cells $[110,111]$. Similarly to DMT1, the IRE/IRP system may not play a role in regulating the normal decline of FPN expression in mammary gland during lactation. The mechanisms regulating the decline in mammary gland FPN throughout lactation are not known.

At the post-translational level, FPN expression is regulated by ubiquitylation through its interaction with hepcidin (HEP). The peptide hormone HEP is secreted mainly by the liver in response to inflammation, hypoxia and changes in body iron stores levels [112]. HEP acts as a negative regulator of the iron export to the plasma, as it binds the iron exporter FPN and induces its internalization and degradation [113]. The FPN-HEP regulatory axis has been shown to be present and functional in human MECs. Pro-HEP and HEP were detected in human 
MECs $[100,114]$ and HEP-mediated degradation of FPN in these cells was associated with an increase in ferritin levels and an elevated labile iron pool [100]. HEP and its precursor pro-HEP has been shown to be secreted into milk [114]. It is unknown whether the milk peptides originate in the mammary gland tissue or are transported from the plasma. Moreover, the role of the FPN-HEP regulatory axis in the MECs remains largely unknown.

Oxidation of Iron at the Apical Membrane Iron oxidation in the extracellular compartment seems to be essential for its transport out of the cell by FPN. Ceruloplasmin (CP) plays an essential role in mammalian iron homeostasis as the major multicooper ferroxidase in blood. Absence of multicopper oxidases, such as $\mathrm{CP}$, leads to cellular iron retention due to an ubiquitin-mediated FPN internalization and degradation [115]. A marked impairment in iron efflux was observed in reticuloendothelial cells and hepatocytes of CP-null mice suggesting that this multicopper oxidase plays a vital role in the movement of iron out of these cells [116]. However, it is unclear if CP is the only ferroxidase involved in iron release from body stores since patients with aceruloplasminemia [117] and CP-null mice [116] present moderate anemia. In enterocytes, FPN-mediated efflux of $\mathrm{Fe}^{2+}$ is coupled to its oxidation by hephaestin, a transmembrane-bound CP homologue [118-120]. Milk CP is specifically synthetized by the mammary gland and secreted into milk [121-123]. Zyklopen, a membrane bound protein of the multicooper ferrioxidase family with high sequence identity to hephaestin and $\mathrm{CP}$, was found to be present in mouse mammary tissue and, in MCF7 and T47D cells [124]. Interestingly, casein was shown to oxidize $\mathrm{Fe}^{2+}$ and the resulting $\mathrm{Fe}^{3+}$ is complexed to this protein [125]. However, the precise mechanism by which iron transported out of the cytosol by FPN and whether zyklopen is required for this process still remains elusive.

Figure 3 shows a representation of the proposed mechanisms that regulate the iron concentration in milk. Holotransferrin in the circulation is taken up by the TfR at the basal side of MECs. The transferrin-TfR complex is endocytosed into a low $\mathrm{pH}$ endosomal compartment where iron is released from transferrin. Iron is likely oxidized in the endosomal compartment by a ferroxidase of the STEAP family and then transported out from the endosome to the cytoplasm via DMT1. Once in the cytosol, iron may be utilized by MECs because lactation is an energy-expensive process or transferred through the cytoplasm for its secretion into milk by an unknown mechanism. Finally, iron may be transported into the Golgi and/or secretory compartment, where it can then bind to iron-binding proteins, and is secreted by exocytosis. Iron in the cytoplasm may also be utilized in the synthesis of iron-containing enzymes, such as xanthine oxidase, which are secreted with the milk fat globule.

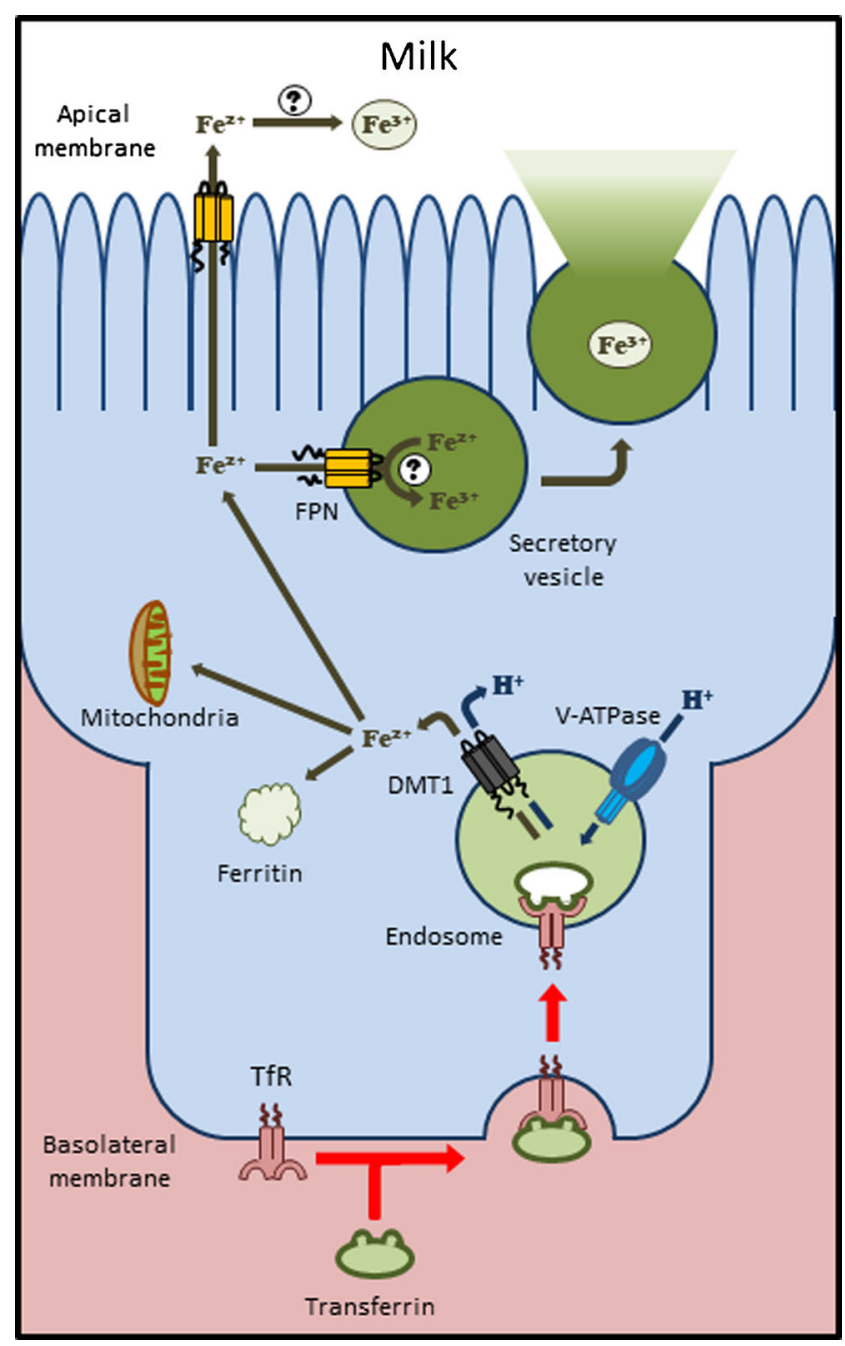

Fig. 3 Iron transport in mammary epithelial cells. Iron is acquired by the MEC from holotransferrin trough a TfR-mediated process at the basolateral membrane. After endocytosis, the endosome is acidified by a V-ATPase $\mathrm{H}^{+}$ pump causing the dissociation of iron from the transferrin-TfR complex. Thereafter, iron is transported out of the endosome to the cytosol by the $\mathrm{H}^{+}$coupled transporter DMT1 (SLC31A2). Once in the cytosol most intracellular iron binds to ferritin, the major storage form of iron. A small pool of soluble iron is maintained for many cellular functions, such as energy transduction by mitochondrial cytochromes. Ferroportin-1 (SLC4OA1) is the only known transport mechanism that mediates cellular iron efflux. Iron can be transported out of the cell directly into the milk by FPN. Alternatively, it was suggested that FPN may be involved in the intracellular trafficking of iron between the cytosol and organelles. In this model, iron is finally secreted into milk by exocytosis of secretory vesicles at the apical membrane. The molecular entity that mediates iron oxidation after its transport by FPN remains unknown

\section{Copper Transport in the Mammary Gland}

Cooper concentration in milk is 3 to 4 times lower than serum [126] indicating that its secretion into milk is regulated by the mammary gland. The newborn have ample stores of copper in the liver, even 10 times higher than adult levels, that could be mobilized during early life [63]. However, neonates with poor liver copper stores (e.g. premature human infants) are more 
vulnerable to nutritional copper deficiency [127, 128]. Moreover, toxic-milk (tx) mice pups die in the second week from severe copper deficiency due to low liver copper stores and low intakes from maternal copper-deficient milk [129]. Hence, maternal milk copper may contribute significantly to the nutritional copper status of the newborn, especially in those with low liver copper stores such as premature human infants.

Epithelial Copper Uptake Pathway CTR1 transporter, a member of the SLC31 family, has been found to be essential for mammalian cellular copper uptake as Slc31a1-knockout mice die at early gestational stage [130]. Structural studies suggest that CTR1 assembles into a homotrimer in a channellike architecture that forms a membrane spanning pore $[131,132]$. The monomers are predicted to have three transmembrane domains with the $\mathrm{N}$-terminal domain located at the extracellular side and C-terminal domain in the cytosol. Human CTR1 displays selectivity and high affinity for the reduced $\mathrm{Cu}$ (I) form (with an apparent $K_{m}$ value of $1.7 \mu \mathrm{M}$ ) when overexpressed in HEK293 cells [133]. CTR1-mediated copper uptake has been shown to be an energy-independent process and is stimulated by extracellular low $\mathrm{pH}$ and high $\mathrm{K}^{+}$ concentration. A model has been proposed to address the mechanism of CTR1-mediated copper transport through the plasma membrane suggesting that CTR1 acts as a membrane transporter that mediates the transport of copper directly from the extracellular medium to the cytosol. The N-terminal domain binds and facilitates the transfer of copper through the pore channel domain [134]. Cooper circulates mainly bound to $\mathrm{CP}$ and, to a lower degree, to other plasma protein carriers and low molecular weight chelating agents. However, functional and/or physical interactions between the $\mathrm{N}$-terminal domain of CTR1 and extracellular copper carriers have not been reported so far. Moreover, the mechanisms by which copper is reduced prior to transport through CTR1 are unknown.

The mechanism that mediates copper uptake into the MECs remains also largely unknown. Copper uptake into MECs is likely mediated by CTR1, however it is unknown how this metal is delivered to MECs from its plasma protein carriers. This transporter has been shown to be expressed in rat mammary gland $[135,136]$ both at the plasma membrane and intracellular vesicles [135]. A greater basal mammary gland copper uptake was observed during early lactation compared with late lactation. Furthermore, suckling resulted in enhanced copper transport into the mammary gland. However, mammary gland Ctr1 mRNA and protein levels were not significantly different between early and late lactation. These results suggest that the decrease observed in mammary gland copper uptake as lactation progeses may be primarily a result of declining copper levels in the maternal circulation [135]. In contrast, prolactin stimulation increases copper secretion across MECs with a concomitant increase of CTR1 plasma membrane abundance [135], suggesting that this transporter is expressed at the intracellular vesicular compartment and may be recruited to the membrane when needed for copper export.

Copper Transport Within the Cell Following entry via the CTR1, copper is delivered to several copper chaperones, which subsequently transfer the metal to specific targets. However, copper binding to specific chaperone proteins seems not to be the rate-limiting step in copper acquisition by the cell. Recently, the tripeptide glutathione has been shown to play an important role in copper handling immediately after its transport by CTR1 [137]. Glutathione may be involved in the transfer of copper to specific chaperone proteins (for review see [138]). Copper transfer from the uptake system to the export system is carried out by the copper chaperone protein ATOX1 (for review see [139]). ATOX1 has been shown to be expressed in rat mammary gland [135], however its role in copper delivery to the export system has not been proven yet.

Epithelial Copper Efflux Pathway Copper transport out of the cytosol across cellular membranes is mediated by two P-type ATPases, namely ATP7A and ATP7B [139]. ATP7A and ATP7B play major roles in cellular copper homeostasis and their absence or malfunction leads to genetically inherited disorders, Menkes and Wilson disease, respectively. Under normal conditions, both proteins are predominantly located at the trans-Golgi network of the cell mediating the delivery of copper to the newly synthesized cuproenzymes within the secretory pathway. High intracellular copper levels prompt the redistribution of these proteins to different vesicular compartments to eliminate excess copper from the cell.

Copper delivery to the milk seems to be facilitated by both ATP7A and ATP7B copper-ATPases. ATP7A [140] and ATP7B [141] have been reported to be expressed in the mammary gland. The intracellular distribution of ATP7A and ATP7B changes during lactation. In non-lactating mammary gland these proteins have tight perinuclear localization $[140,141]$, consistent with the trans-Golgi network. In contrast, ATP7A and ATP7B show a granular diffuse cytoplasmic pattern during lactation [140, 141]. However, ATP7A and ATP7B seem to have different roles during lactation. The involvement of ATP7B in copper export from the mammary gland is evident from the phenotypes of $t x$ and Atp $7 b$ - knockout mice. The $t x$ mutation in mice results in defective mammary gland ATP7B impairing copper export into milk leading to neonatal death from copper deficiency [141]. Similar copper perinatal deficiency is observed in Atp $7 b$ - knockout mice [142]. Interestingly, some copper is being delivered into milk even in the absence of functional ATP7B (20-30 \% of normal), suggesting that an ATP7B-independent pathway partially compensates for ATP7B lack of function. ATP7B appears to be the primary transporter mediating copper secretion into 
milk by delivering copper to $\mathrm{CP}$ and to secretory vesicles. The role of ATP7A in copper secretion into milk remains unclear. It was proposed to ATP7A could be involved in copper delivering to $\mathrm{CP}$ and that this pathway may account for the $20-30 \%$ of the remaining secretion of copper into milk in the tx mice $[143,144]$. Alternatively, it was proposed that ATP7A located at the apical membrane could export copper directly into the milk [135]. A role of ATP7A in the removal of copper from the mammary gland back into the circulation was also proposed [143].

Figure 4 summarizes the main mechanisms proposed to be involved in MECs secretion of cooper into the milk.

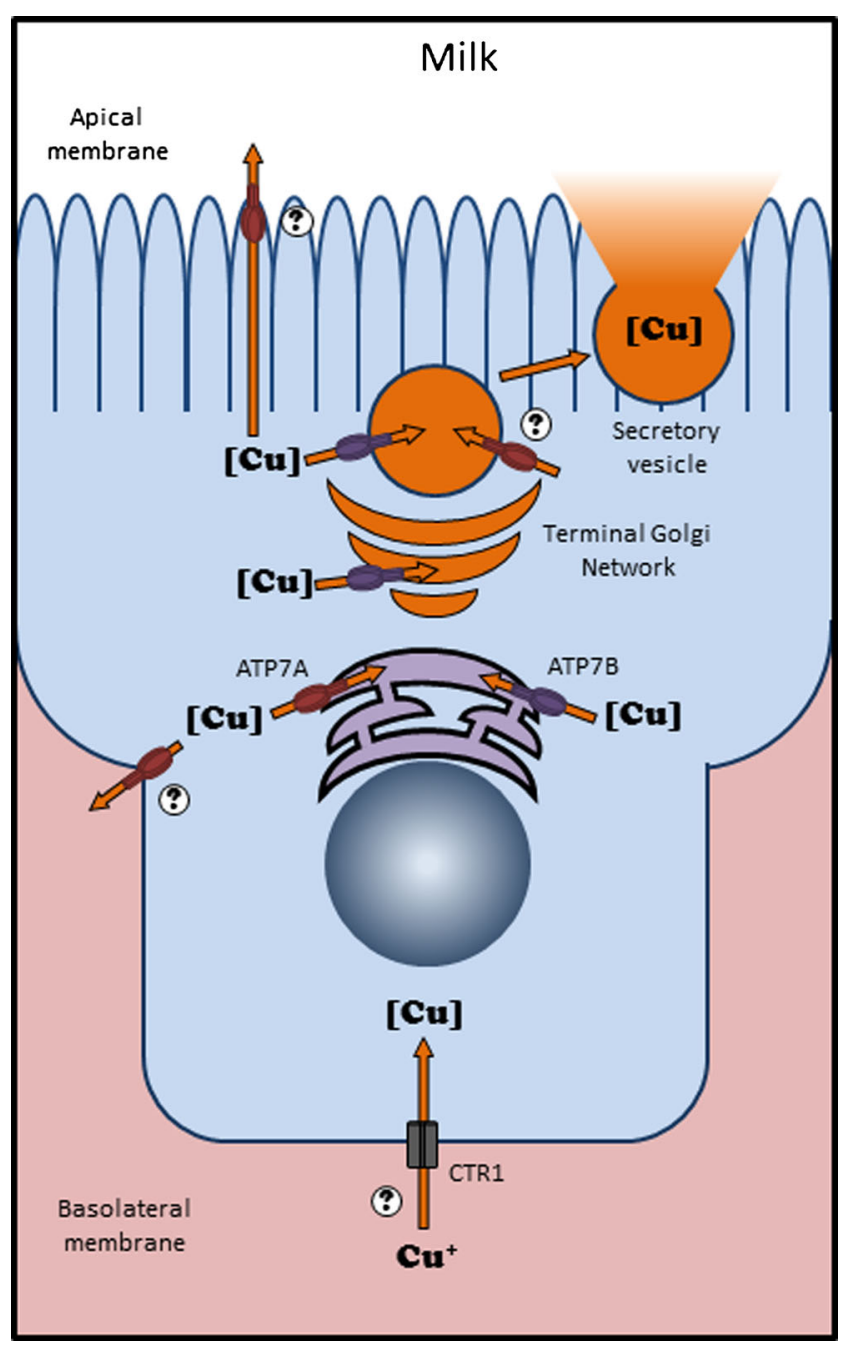

Fig. 4 Copper transport in the mammary epithelial cells. The CTR1 (SLC31A1) transporter mediates the uptake of copper into the MECs. Two P-type ATPases, namely ATP7A and ATP7B, mediate copper secretion into milk. ATP7B appears to be the main regulator of copper secretion into milk by delivery copper to ceruloplasmin and to secretory vesicles. The role of ATP7A in copper secretion into milk remains unclear. It was proposed that the ATP7A at the apical membrane may directly export copper into the milk, or that it could be involved in copper delivery to ceruloplasmin at the secretory vesicles. Finally, ATP7A located at the basolateral membrane may serve to remove copper from the mammary gland back into the circulation

\section{Transport of Water Soluble Vitamins into Milk}

Water soluble vitamins (ascorbic acid, biotin, folate, cobalamin, riboflavin, thiamin, niacin, pantothenic acid and pyridoxine) play critical roles in maintaining normal metabolic, energy, differentiation, and growth status of mammalian cells. Since the mammary gland cannot synthesize vitamins, these micronutrients must be obtained from exogenous sources. Vitamin content in human milk is directly related to the mother's vitamin status [145]. Since water soluble vitamins are not stored to a large extent in the body their concentrations in milk are more responsive to maternal dietary intake. In general, the quantities of these vitamins in human milk are higher than their levels in plasma, suggesting that water soluble vitamins are actively secreted into milk. However, the regulation of water soluble vitamin levels in milk seems to be a complex process involving several different vitamin-specific transport systems. The concentrations of niacin, pantothenic acid and biotin in rat milk were not decreased with lowvitamin diet, but were increased with the high-vitamin mixture diet [146]. On the other hand, the concentrations of thiamine, riboflavin, pyridoxine and cobalamin were decreased with low-vitamin diet, but were not increased with the highvitamin diet [146]. The folate concentration in rat milk remained constant regardless of folate intake [146]. These results suggest that the mammary gland has a remarkable capacity for controlling critical levels of water soluble vitamins in breast milk. Numerous proteins implicated in their intestinal absorption as well as transport into cells of systemic tissues have been described [147] (Table 1). Although, our understanding of the transport of water soluble vitamins has greatly improved in recent years the transport mechanisms involved in vitamin secretion into milk remain largely unknown.

The multidrug transporter breast cancer resistance protein (BCRP/ABCG2) has been proposed to mediate riboflavin transport into milk [148]. BCRP belongs to in the superfamily of $\mathrm{ABC}$ transporters and is expressed in the apical membranes of intestine, kidney and placenta epithelia and in the hepatocyte bile canalicular membrane. BCRP seems to have a xenobiotic protective function by pumping a wide variety of endogenous and exogenous compounds out of the cell. Riboflavin (vitamin B2) plays key metabolic roles in carbohydrate, amino acid, and lipid metabolism and in the conversion of folic acid and vitamin B6 compounds into their active coenzyme forms. The most important biologically active forms of riboflavin are flavin mononucleotide and flavin adenine dinucleotide. They act as intermediaries in the transfer of electrons in biological oxidation-reduction reactions. Riboflavin milk content is high in early lactation and declines thereafter [145]. In mouse mammary gland, Abcg2 was found to be highly expressed during late pregnancy and lactation [149]. Abcg2 was detected primarily in the apical 
Table 1 List of transporters known to be involved in the transport of water soluble vitamins tamins concentrations were taken from $[52,145,174]$

\begin{tabular}{|c|c|c|c|}
\hline \multirow[t]{2}{*}{ Vitamin } & \multirow[t]{2}{*}{ Milk concentration $^{\mathrm{a}}$} & \multicolumn{2}{|l|}{ Transporter family } \\
\hline & & SLC & $\mathrm{ABC}$ \\
\hline \multirow[t]{2}{*}{ Thiamine (B1) } & $200 \mu \mathrm{g} / \mathrm{L}$ & SLC19A2 (ThTr1) & \\
\hline & $350-500 \mu \mathrm{g} / \mathrm{L}$ & $\begin{array}{l}\text { SLC19A3 (ThTr2) } \\
\text { SLC52A1 (RFVT1) }\end{array}$ & ABCG2 (BCRP) \\
\hline Riboflavin (B2) & & SLC52A2 (RFVT2) & \\
\hline Niacin (B3) & $1-2 \mathrm{mg} / \mathrm{L}$ & $\begin{array}{l}\text { SLC52A3 (RFVT3) } \\
\text { SLC5A8 (SMCT1) }\end{array}$ & \\
\hline Pantothenic acid (B5) & $2-10 \mu \mathrm{g} / \mathrm{L}$ & SLC5A6 (SMVT) & \\
\hline Pyridoxine (B6) & $50-250 \mu \mathrm{g} / \mathrm{L}$ & unknown & \\
\hline Biotin (B7) & $10-25 \mu \mathrm{g} / \mathrm{L}$ & SLC5A6 (SMVT) & \\
\hline Folate (B9) & $80-100 \mu \mathrm{g} / \mathrm{L}$ & SLC46A1 (PCFT) & ABCC1-4 (MRP1-4) \\
\hline Cobalamin (B12) & $0.3-3.2 \mu \mathrm{g} / \mathrm{L}$ & $\begin{array}{l}\text { SLC19A1 (RFC) } \\
\text { unknown }\end{array}$ & ABCC1 (MRP1) \\
\hline Ascorbic acid (C) & $50-60 \mathrm{mg} / \mathrm{L}$ & SLC23A1 (SVCT1) & \\
\hline & & SLC23A2 (SVCT2) & \\
\hline
\end{tabular}

membrane of alveolar epithelial cells, but not in main ducts. Since milk secretion of riboflavin was not completely abolished in the Abcg2-knockout mice ( $\sim 60 \%$ decrease), a second independent pathway involved in riboflavin transfer into milk was proposed [148]. The mechanisms that mediate basolateral riboflavin uptake in MECs are currently unknown but, recently a novel family of mammalian riboflavin transporters, RFVT/SLC52, was identified (see [150] for review). This family is composed by three members, RFVT1 (SLC52A1), RFVT2 (SLC52A2) and RFVT3 (SLC52A3), which are ubiquitously expressed. All of them exhibit high affinity for riboflavin, however, the transport mechanisms are still unclear. Interestingly, RFVT3 is expressed in the luminal side of intestinal cells where it is thought to mediate riboflavin absorption [151, 152]. It remains to be determined if these proteins play a role in riboflavin secretion into milk.

A receptor mediated system for cobalamin uptake in human mammary cells was proposed [153]. Cobalamin is transported in plasma bound to a protein called transcobalamin II. However, in human milk cobalamin is bound exclusively to the glycoprotein haptocorrin [154]. It has been shown that cultured human MECs exhibit high affinity for the transcobalamin II/cobalamin complex but not for free cobalamin [59]. This receptor mediated system for cobalamin in MECs was proposed to transport vitamin B12 into the cell. After internalization, cobalamin is transported into the milk where it is bound exclusively to the glycoprotein haptocorrin. However the mechanisms that mediate the transfer of cobalamin from transcobalamin II to haptocorrin are not yet known.

Thiamine pyrophosphate is a coenzyme required for several key enzymes involved in energy production from carbohydrate and amino acid metabolism. This vitamin is transported across the plasma membrane by two members of the SLC19 family, ThTr1 (SLC19A2) and ThTr2 (SLC19A3) [155]. These two proteins may have different roles in thiamine transport across epithelia [156]. Studies in Slc19a3- and Slc19a2-null mice indicate that ThTr2 is a main regulator of intestinal thiamine absorption [157]. The expression of the thiamine transporter $\operatorname{Th} \operatorname{Tr} 2$, but not $\operatorname{Th} \operatorname{Tr} 1$, has been reported to be regulated by the hypoxia inducible factor- $1 \alpha$ in the breast cancer cell line model BT474 [158]. However, the expression of transporters from the SLC19 family in mammary gland has not yet been reported. Moreover, there is no information available about the transport mechanisms that mediate the secretion of thiamine into milk. Thiamine concentration in milk increases up to 10 -fold during lactation [145]. Importantly, thiamine levels in breast milk are directly influenced by the maternal thiamine status. Maternal supplementation increases thiamine milk levels to a certain extent indicating that there is a limit in the amount that can be transferred into milk [52].

To our knowledge, there is no information available about the transport mechanisms involved in the secretion of ascorbic acid, biotin, folate, niacin, pantothenic acid and pyridoxine into the milk. Several transporters of the SLC family have been shown to mediate cellular transport of these vitamins (Table 1). SMVT (SLC5A6) is a widely distributed $\mathrm{Na}^{+}$-dependent cotransporter that mediates the uptake of pantothenic acid and biotin $[159,160]$. SMCT1 (SLC5A8) is a $\mathrm{Na}^{+}$coupled monocarboxylate cotransporter widely expressed in the body that mediates the transport of nicotinate among other substrates [161-163]. SVCT1 (SLC23A1) and SVCT2 (SLC23A2) mediate specifically the transport of ascorbic acid in a $\mathrm{Na}^{+}$-dependent cotransport mechanism [164-167]. 
Folate has been shown to be transported by several members of the SLC and ABC transporter families (for review see [155, $168,169])$. RFC (SLC19A1) is an organic anion antiporter that mediates the delivery of folate to systemic tissues at neutral pH. PCFT (SLC46A1) transports folic acid and reduced folates with high affinity at low $\mathrm{pH}$ (optimal $\mathrm{pH}=5.0-5.5$ ). Many organic anion facilitative transporters from the SLC21 family have also been shown to transport folates. Cellular efflux of folates is mediated by multidrug resistance associated proteins (ABCC/MRP) MRP1-4, which belong to the ATP-binding cassette superfamily (reviewed in $[170,171])$. Characterizing the expression and the role of these transporters in MECs will be essential to improve our understanding of water soluble vitamin secretion into milk.

\section{Concluding Remarks}

The mammary gland has a unique capacity to tightly regulate milk secretion of macro and micro nutrients and thereby protect the offspring from maternal deficiency or excess of these elements while facing the challenge of maintaining its own homeostasis. The secretion of milk nutrients by MECs is a complex process that involves the orchestration of several transport mechanisms located at their apical and basolateral membranes. Over the past decade, substantial progress has been made in the understanding of transport mechanisms that regulate the concentration of milk nutrients. Several transporters of the ABC and SLC superfamilies play a major role in milk nutrient secretion. However, several important questions remain to be addressed.

Much effort is required in the field of calcium secretion into milk as the mechanism of calcium entry remains unclear and there is no consensus in the model of calcium secretion (e.g. Golgi pathway versus apical active transport). Extensive research in the field of MECs transport mechanisms is required for a deeper understanding of the role of calcium transporters in the development and progression of breast cancer diseases in order to provide novel therapeutic strategies.

Moreover, further characterization and a better understanding of the transport mechanisms involved in micronutrient secretion into milk is needed. The exact role of TfR, DMT1 and FPN in iron secretion into milk and the regulation of iron uptake by the MECs remain largely unknown. Whether the IRE or the non-IRE DMT1 and FPN variants are the predominant forms present in the mammary gland needs to be investigated. Since lactation is an energy-expensive process, it cannot be excluded that the expression of these proteins in the mammary gland during lactation may simply reflect an increased metabolic demand for iron to be utilized for example by the oxidative phosphorylation cytochrome system. If this is the case, further work is needed to identify the transport mechanisms that regulate iron secretion into milk. In particular, the transport mechanisms that mediate copper uptake in MECs and the secretion of water soluble vitamins into milk remain to be elucidated.

\section{References}

1. Fromter E, Diamond J. Route of passive ion permeation in epithelia. Nat New Biol. 1972;235(53):9-13.

2. Itoh M, Bissell MJ. The organization of tight junctions in epithelia: implications for mammary gland biology and breast tumorigenesis. J Mammary Gland Biol Neoplasia. 2003;8(4):449-62.

3. Nguyen DA, Neville MC. Tight junction regulation in the mammary gland. J Mammary Gland Biol Neoplasia. 1998;3(3):233-46.

4. McManaman JL, Neville MC. Mammary physiology and milk secretion. Adv Drug Deliv Rev. 2003;55(5):629-41.

5. Neville MC et al. Studies in human lactation-milk volume and nutrient composition during weaning and lactogenesis. Am J Clin Nutr. 1991;54(1):81-92.

6. Neville MC, Peaker M. Secretion of calcium and phosphorus into milk. J Physiol Lond. 1979;290(May):59-67.

7. Neville MC, Peaker M. Calcium fluxes in mouse mammary tissue in vitro: intracellular and extracellular calcium pools. J Physiol. 1982;323:497-517.

8. Shennan DB, Peaker M. Transport of milk constituents by the mammary gland. Physiol Rev. 2000;80(3):925-51.

9. Gao B et al. Functional properties of a new voltage-dependent calcium channel alpha(2)delta auxiliary subunit gene (CACN A2D2). J Biol Chem. 2000;275(16):12237-42.

10. Bertolesi GE et al. The $\mathrm{Ca}(2+)$ channel antagonists mibefradil and pimozide inhibit cell growth via different cytotoxic mechanisms. Mol Pharmacol. 2002;62(2):210-9.

11. Baldi C, Vazquez G, Boland R. Capacitative calcium influx in human epithelial breast cancer and non-tumorigenic cells occurs through $\mathrm{Ca} 2+$ entry pathways with different permeabilities to divalent cations. J Cell Biochem. 2003;88(6):1265-72.

12. Hoenderop JG et al. Molecular identification of the apical $\mathrm{Ca} 2+$ channel in 1, 25-dihydroxyvitamin D3-responsive epithelia. J Biol Chem. 1999;274(13):8375-8.

13. Peng JB et al. Molecular cloning and characterization of a channellike transporter mediating intestinal calcium absorption. J Biol Chem. 1999;274(32):22739-46.

14. Hoenderop JG et al. Function and expression of the epithelial $\mathrm{Ca}(2+)$ channel family: comparison of mammalian $\mathrm{ECaC1}$ and 2. J Physiol. 2001;537(Pt 3):747-61.

15. Loffing $\mathrm{J}$ et al. Distribution of transcellular calcium and sodium transport pathways along mouse distal nephron. Am J Physiol Renal Physiol. 2001;281(6):F1021-7.

16. Zhuang L et al. Calcium-selective ion channel, CaT1, is apically localized in gastrointestinal tract epithelia and is aberrantly expressed in human malignancies. Lab Invest. 2002;82(12): 1755-64.

17. Sudlow AW, Burgoyne RD. A hypo-osmotically induced increase in intracellular $\mathrm{Ca} 2+$ in lactating mouse mammary epithelial cells involving Ca2+ influx. Pflugers Arch. 1997;433(5): 609-16.

18. Enomoto $\mathrm{K}$ et al. Mechanically induced electrical responses in murine mammary epithelial cells in primary culture. FEBS Lett. 1987;223(1):82-6.

19. Enomoto $\mathrm{K}$ et al. Mechanically induced electrical and intracellular calcium responses in normal and cancerous mammary cells. Cell Calcium. 1992;13(8):501-11. 
20. Enomoto $\mathrm{K}$ et al. Proliferation-associated increase in sensitivity of mammary epithelial cells to inositol-1,4,5-trisphosphate. Cell Biochem Funct. 1993;11(1):55-62.

21. Flezar M, Heisler S. P2-purinergic receptors in human breast tumor cells: coupling of intracellular calcium signaling to anion secretion. J Pharmacol Exp Ther. 1993;265(3):1499-510.

22. VanHouten JN, Neville MC, Wysolmerski JJ. The calcium-sensing receptor regulates plasma membrane calcium adenosine triphosphatase isoform 2 activity in mammary epithelial cells: a mechanism for calcium-regulated calcium transport into milk. Endocrinology. 2007;148(12):5943-54.

23. Buxton IL, Yokdang N, Matz RM. Purinergic mechanisms in breast cancer support intravasation, extravasation and angiogenesis. Cancer Lett. 2010;291(2):131-41.

24. Neville MC et al. Calcium partitioning in human and bovine milk. $\mathrm{J}$ Dairy Sci. 1994;77(7):1964-75.

25. Van Baelen K et al. The $\mathrm{Ca} 2+/ \mathrm{Mn} 2+$ pumps in the Golgi apparatus. Biochim Biophys Acta. 2004;1742(1-3):103-12.

26. Wuytack F, Raeymaekers L, Missiaen L. Molecular physiology of the SERCA and SPCA pumps. Cell Calcium. 2002;32(5-6): 279-305.

27. Wootton LL et al. The expression, activity and localisation of the secretory pathway $\mathrm{Ca} 2+-\mathrm{ATPase}$ (SPCA1) in different mammalian tissues. Biochim Biophys Acta. 2004;1664(2):189-97.

28. Vanoevelen $\mathrm{J}$ et al. The secretory pathway $\mathrm{Ca} 2+/ \mathrm{Mn} 2+-\mathrm{ATPase} 2$ is a Golgi-localized pump with high affinity for $\mathrm{Ca} 2+$ ions. J Biol Chem. 2005;280(24):22800-8.

29. Hu $\mathrm{Z}$ et al. Mutations in ATP2C1, encoding a calcium pump, cause Hailey-Hailey disease. Nat Genet. 2000;24(1):61-5.

30. Faddy HM et al. Localization of plasma membrane and secretory calcium pumps in the mammary gland. Biochem Biophys Res Commun. 2008;369(3):977-81.

31. Reinhardt $\mathrm{TA}$ et al. $\mathrm{Ca}(2+)$-ATPase protein expression in mammary tissue. Am J Physiol Cell Physiol. 2000;279(5):C1595-602.

32. Duncan JS, Burgoyne RD. Characterization of the effects of $\mathrm{Ca} 2+$ depletion on the synthesis, phosphorylation and secretion of caseins in lactating mammary epithelial cells. Biochem J. 1996;317(Pt 2): 487-93.

33. Ginger MR, Grigor MR. Comparative aspects of milk caseins. Comp Biochem Physiol B Biochem Mol Biol. 1999;124(2): 133-45.

34. Oda K. Calcium depletion blocks proteolytic cleavages of plasma protein precursors which occur at the Golgi and/or trans-Golgi network. Possible involvement of $\mathrm{Ca}(2+)$-dependent Golgi endoproteases. J Biol Chem. 1992;267(24):17465-71.

35. Taylor RS et al. Characterization of the Golgi complex cleared of proteins in transit and examination of calcium uptake activities. Mol Biol Cell. 1997;8(10):1911-31.

36. Reinhardt TA et al. Null mutation in the gene encoding plasma membrane $\mathrm{Ca} 2+-\mathrm{ATPase}$ isoform 2 impairs calcium transport into milk. J Biol Chem. 2004;279(41):42369-73.

37. James $\mathrm{P}$ et al. Identification and primary structure of a calmodulin binding domain of the Ca2+ pump of human erythrocytes. J Biol Chem. 1988;263(6):2905-10.

38. Reinhardt TA, Horst RL. Ca2 -ATPases and their expression in the mammary gland of pregnant and lactating rats. Am J Physiol. 1999;276(4 Pt 1):C796-802.

39. Strehler EE, Zacharias DA. Role of alternative splicing in generating isoform diversity among plasma membrane calcium pumps. Physiol Rev. 2001;81(1):21-50.

40. Jackisch $\mathrm{C}$ et al. Delayed micromolar elevation in intracellular calcium precedes induction of apoptosis in thapsigargin-treated breast cancer cells. Clin Cancer Res. 2000;6(7):2844-50.

41. Berridge MJ, Bootman MD, Roderick HL. Calcium signalling: dynamics, homeostasis and remodelling. Nat Rev Mol Cell Biol. 2003;4(7):517-29.
42. Carafoli E et al. Generation, control, and processing of cellular calcium signals. Crit Rev Biochem Mol Biol. 2001;36(2): 107-260.

43. Michalak M, Mariani P, Opas M. Calreticulin, a multifunctional $\mathrm{Ca} 2+$ binding chaperone of the endoplasmic reticulum. Biochem Cell Biol. 1998;76(5):779-85.

44. Lin $\mathrm{P}$ et al. The mammalian calcium-binding protein, nucleobindin (CALNUC), is a Golgi resident protein. J Cell Biol. 1998;141(7): 1515-27.

45. Lin $\mathrm{P}$ et al. Overexpression of CALNUC (nucleobindin) increases agonist and thapsigargin releasable $\mathrm{Ca} 2+$ storage in the Golgi. J Cell Biol. 1999;145(2):279-89.

46. Bolanz KA, Hediger MA, Landowski CP. The role of TRPV6 in breast carcinogenesis. Mol Cancer Ther. 2008;7(2):271-9.

47. Lee WJ et al. Expression of plasma membrane calcium pump isoform mRNAs in breast cancer cell lines. Cell Signal. 2002;14(12):1015-22.

48. Dhennin-Duthille I et al. High expression of transient receptor potential channels in human breast cancer epithelial cells and tissues: correlation with pathological parameters. Cell Physiol Biochem. 2011;28(5):813-22.

49. Li M et al. Mammary-derived signals activate programmed cell death during the first stage of mammary gland involution. Proc Natl Acad Sci U S A. 1997;94(7):3425-30.

50. VanHouten $\mathrm{J}$ et al. PMCA 2 regulates apoptosis during mammary gland involution and predicts outcome in breast cancer. Proc Natl Acad Sci U S A. 2010;107(25):11405-10.

51. Peters AA et al. Calcium channel TRPV6 as a potential therapeutic target in estrogen receptor-negative breast cancer. Mol Cancer Ther. 2012;11(10):2158-68.

52. Lonnerdal B. Effects of maternal dietary intake on human milk composition. J Nutr. 1986;116(4):499-513.

53. Siimes MA, Vuori E, Kuitunen P. Breast milk iron-a declining concentration during the course of lactation. Acta Paediatr Scand. 1979;68(1):29-31.

54. Vaughan LA, Weber CW, Kemberling SR. Longitudinal changes in the mineral content of human milk. Am J Clin Nutr. 1979;32(11):2301-6.

55. Keen CL et al. Developmental changes in composition of rat milk: trace elements, minerals, protein, carbohydrate and fat. J Nutr. 1981;111(2):226-36.

56. Lonnerdal B. Copper nutrition during infancy and childhood. Am J Clin Nutr. 1998;67(5 Suppl):1046S-53S.

57. Krebs NF et al. The effects of a dietary zinc supplement during lactation on longitudinal changes in maternal zinc status and milk zinc concentrations. Am J Clin Nutr. 1985;41(3):560-70.

58. Domellof $\mathrm{M}$ et al. Iron, zinc, and copper concentrations in breast milk are independent of maternal mineral status. Am J Clin Nutr. 2004;79(1):111-5.

59. Hannan MA et al. Maternal milk concentration of zinc, iron, selenium, and iodine and its relationship to dietary intakes. Biol Trace Elem Res. 2009;127(1):6-15.

60. Vuori $\mathrm{E}$ et al. The effects of the dietary intakes of copper, iron, manganese, and zinc on the trace element content of human milk. Am J Clin Nutr. 1980;33(2):227-31.

61. Griffin IJ, Abrams SA. Iron and breastfeeding. Pediatr Clin North Am. 2001;48(2):401-13.

62. Dallman PR. Progress in the prevention of iron deficiency in infants. Acta Paediatr Scand Suppl. 1990;365:28-37.

63. Casey C, SAa.ZP. Handbook of milk composition. Academic Press; 1995

64. Ohgami RS et al. Identification of a ferrireductase required for efficient transferrin-dependent iron uptake in erythroid cells. Nat Genet. 2005;37(11):1264-9.

65. Knutson MD. Steap proteins: implications for iron and copper metabolism. Nutr Rev. 2007;65(7):335-40. 
66. Lambe $\mathrm{T}$ et al. Identification of a Steap3 endosomal targeting motif essential for normal iron metabolism. Blood. 2009;113(8):1805-8.

67. Fleming MD et al. Nramp2 is mutated in the anemic Belgrade (b) rat: evidence of a role for Nramp2 in endosomal iron transport. Proc Natl Acad Sci U S A. 1998;95(3):1148-53.

68. Touret $\mathrm{N}$ et al. Dynamic traffic through the recycling compartment couples the metal transporter Nramp2 (DMT1) with the transferrin receptor. J Biol Chem. 2003;278(28):25548-57.

69. Canonne-Hergaux F et al. Characterization of the iron transporter DMT1 (NRAMP2/DCT1) in red blood cells of normal and anemic $\mathrm{mk} / \mathrm{mk}$ mice. Blood. 2001;98(13):3823-30.

70. Gruenheid $\mathrm{S}$ et al. The iron transport protein NRAMP2 is an integral membrane glycoprotein that colocalizes with transferrin in recycling endosomes. J Exp Med. 1999;189(5):831-41.

71. Gunshin $\mathrm{H}$ et al. Cloning and characterization of a mammalian protoncoupled metal-ion transporter. Nature. 1997;388(6641):482-8.

72. Nevo Y, Nelson N. The NRAMP family of metal-ion transporters. Biochim Biophys Acta. 2006;1763(7):609-20.

73. Zhao $\mathrm{N}$ et al. ZRT/IRT-like protein 14 (ZIP14) promotes the cellular assimilation of iron from transferrin. J Biol Chem. 2010;285(42): 32141-50.

74. Pinilla-Tenas JJ et al. Zip14 is a complex broad-scope metal-ion transporter whose functional properties support roles in the cellular uptake of zinc and nontransferrin-bound iron. Am J Physiol Cell Physiol. 2011;301(4):C862-71.

75. Liuzzi JP et al. Zip14 (Slc39a14) mediates non-transferrin-bound iron uptake into cells. Proc Natl Acad Sci U S A. 2006;103(37):13612-7.

76. Dong XP et al. The type IV mucolipidosis-associated protein TRPML1 is an endolysosomal iron release channel. Nature. 2008;455(7215):992-6.

77. Lopin KV et al. $\mathrm{Fe}(2)(+)$ block and permeation of CaV3.1 (alpha1G) T-type calcium channels: candidate mechanism for non-transferrinmediated Fe(2)(+) influx. Mol Pharmacol. 2012;82(6):1194-204.

78. Kumfu $\mathrm{S}$ et al. T-type calcium channel as a portal of iron uptake into cardiomyocytes of beta-thalassemic mice. Eur J Haematol. 2011;86(2):156-66.

79. Loh TT. Iron in the lactating mammary gland of the rat. Proc Soc Exp Biol Med. 1970;134(4):1070-2.

80. Loh TT, Kaldor I. Studies on the transfer of plasma iron to milk in the lactating rat. Aust J Exp Biol Med Sci. 1976;54(6):587-92.

81. Zhang $\mathrm{P}$ et al. The effect of serum iron concentration on iron secretion into mouse milk. J Physiol. 2000;522(Pt 3):479-91.

82. Moutafchiev DA, Shisheva AC, Sirakov LM. Binding of transferrin-iron to the plasma membrane of a lactating rabbit mammary gland cell. Int J Biochem. 1983;15(5):755-8.

83. Sigman M, Lonnerdal B. Characterization of transferrin receptors on plasma membranes of lactating rat mammary tissue. J Nutr Biochem. 1990;1(5):239-43.

84. Grigor MR, Wilde CJ, Flint DJ. Transferrin receptor activity in rat mammary epithelial cells. Biochem Int. 1988;17(4):747-54.

85. Schulman HM et al. Transferrin receptor and ferritin levels during murine mammary gland development. Biochim Biophys Acta. 1989;1010(1):1-6.

86. Sigman M, Lonnerdal B. Relationship of milk iron and the changing concentration of mammary tissue transferrin receptors during the course of lactation. J Nutr Biochem. 1990;1(11):572-6.

87. Sigman M, Lonnerdal B. Response of rat mammary gland transferrin receptors to maternal dietary iron during pregnancy and lactation. Am J Clin Nutr. 1990;52(3):446-50.

88. Leong WI, Lonnerdal B. Iron transporters in rat mammary gland: effects of different stages of lactation and maternal iron status. Am J Clin Nutr. 2005;81(2):445-53.

89. Gilchrist SE, Alcorn J. Lactation stage-dependent expression of transporters in rat whole mammary gland and primary mammary epithelial organoids. Fundam Clin Pharmacol. 2010;24(2):205-14.
90. Hubert N, Hentze MW. Previously uncharacterized isoforms of divalent metal transporter (DMT)-1: implications for regulation and cellular function. Proc Natl Acad Sci U S A. 2002;99(19): 12345-50.

91. Montalbetti $\mathrm{N}$ et al. Mammalian iron transporters: families SLC11 and SLC40. Mol Aspects Med. 2013;34(2-3):270-87.

92. Kelleher SL, Lonnerdal B. Low vitamin a intake affects milk iron level and iron transporters in rat mammary gland and liver. J Nutr. 2005;135(1):27-32.

93. Agrawal RM, Tripathi AM, Agarwal KN. Cord blood haemoglobin, iron and ferritin status in maternal anaemia. Acta Paediatr Scand. 1983;72(4):545-8.

94. Sisson TR, Lund CJ. The influence of maternal iron deficiency on the newborn. Am J Clin Nutr. 1958;6(4):376-85.

95. Umbreit JN et al. Paraferritin: a protein complex with ferrireductase activity is associated with iron absorption in rats. Biochemistry. 1996;35(20):6460-9.

96. Shi $\mathrm{H}$ et al. A cytosolic iron chaperone that delivers iron to ferritin. Science. 2008;320(5880):1207-10.

97. Abboud S, Haile DJ. A novel mammalian iron-regulated protein involved in intracellular iron metabolism. J Biol Chem. 2000;275(26):19906-12.

98. Donovan A et al. Positional cloning of zebrafish ferroportinl identifies a conserved vertebrate iron exporter. Nature. 2000;403(6771): 776-81.

99. McKie AT et al. A novel duodenal iron-regulated transporter, IREG1, implicated in the basolateral transfer of iron to the circulation. Mol Cell. 2000;5(2):299-309.

100. Pinnix ZK et al. Ferroportin and iron regulation in breast cancer progression and prognosis. Sci Transl Med. 2010;2(43):43ra56.

101. Ward PP et al. Iron status in mice carrying a targeted disruption of lactoferrin. Mol Cell Biol. 2003;23(1):178-85.

102. Delaby $\mathrm{C}$ et al. Presence of the iron exporter ferroportin at the plasma membrane of macrophages is enhanced by iron loading and down-regulated by hepcidin. Blood. 2005;106(12):3979-84.

103. Canonne-Hergaux $\mathrm{F}$ et al. Comparative studies of duodenal and macrophage ferroportin proteins. Am J Physiol Gastrointest Liver Physiol. 2006;290(1):G156-63.

104. Lymboussaki A et al. The role of the iron responsive element in the control of ferroportin1/IREG1/MTP1 gene expression. J Hepatol. 2003;39(5):710-5.

105. Knutson MD et al. Iron loading and erythrophagocytosis increase ferroportin 1 (FPN1) expression in J774 macrophages. Blood. 2003;102(12):4191-7.

106. Yang $\mathrm{F}$ et al. Regulation of reticuloendothelial iron transporter MTP1 (Slc11a3) by inflammation. J Biol Chem. 2002;277(42): 39786-91.

107. Zoller $\mathrm{H}$ et al. Expression of the duodenal iron transporters divalentmetal transporter 1 and ferroportin 1 in iron deficiency and iron overload. Gastroenterology. 2001;120(6):1412-9.

108. Frazer DM et al. Hepcidin expression inversely correlates with the expression of duodenal iron transporters and iron absorption in rats. Gastroenterology. 2002;123(3):835-44.

109. Gambling L et al. Effect of iron deficiency on placental transfer of iron and expression of iron transport proteins in vivo and in vitro. Biochem J. 2001;356(Pt 3):883-9.

110. Zhang DL et al. A ferroportin transcript that lacks an ironresponsive element enables duodenal and erythroid precursor cells to evade translational repression. Cell Metab. 2009;9(5):461-73.

111. Cianetti $\mathrm{L}$ et al. Expression of alternative transcripts of ferroportin-1 during human erythroid differentiation. Haematologica. 2005;90(12):1595-606.

112. Ganz T, Nemeth E. Iron imports. IV. Hepcidin and regulation of body iron metabolism. Am J Physiol Gastrointest Liver Physiol. 2006;290(2):G199-203. 
113. Nemeth $\mathrm{E}$ et al. Hepcidin regulates cellular iron efflux by binding to ferroportin and inducing its internalization. Science. 2004;306(5704):2090-3.

114. Aydin S et al. Concentrations of preptin, salusins and hepcidins in plasma and milk of lactating women with or without gestational diabetes mellitus. Peptides. 2013;49:123-30.

115. De Domenico I et al. Ferroxidase activity is required for the stability of cell surface ferroportin in cells expressing GPI-ceruloplasmin. EMBO J. 2007;26(12):2823-31.

116. Harris $Z L$ et al. Targeted gene disruption reveals an essential role for ceruloplasmin in cellular iron efflux. Proc Natl Acad Sci U S A. 1999;96(19):10812-7.

117. $\mathrm{Xu} \mathrm{X}$ et al. Aceruloplasminemia: an inherited neurodegenerative disease with impairment of iron homeostasis. Ann N Y Acad Sci. 2004;1012:299-305.

118. Anderson GJ et al. The ceruloplasmin homolog hephaestin and the control of intestinal iron absorption. Blood Cells Mol Dis. 2002;29(3):367-75.

119. Petrak J, Vyoral D. Hephaestin-a ferroxidase of cellular iron export. Int J Biochem Cell Biol. 2005;37(6):1173-8.

120. Vulpe CD et al. Hephaestin, a ceruloplasmin homologue implicated in intestinal iron transport, is defective in the sla mouse. Nat Genet. 1999;21(2):195-9.

121. Jaeger JL, Shimizu N, Gitlin JD. Tissue-specific ceruloplasmin gene expression in the mammary gland. Biochem J. 1991;280(Pt 3):671-7.

122. Donley SA et al. Copper transport to mammary gland and milk during lactation in rats. Am J Physiol Endocrinol Metab. 2002;283(4):E667-75.

123. Cerveza PJ et al. Milk ceruloplasmin and its expression by mammary gland and liver in pigs. Arch Biochem Biophys. 2000;373(2):451-61.

124. Chen $\mathrm{H}$ et al. Identification of zyklopen, a new member of the vertebrate multicopper ferroxidase family, and characterization in rodents and human cells. J Nutr. 2010;140(10):1728-35.

125. Emery T. Iron oxidation by casein. Biochem Biophys Res Commun. 1992;182(3):1047-52.

126. Lonnerdal B. Trace element transport in the mammary gland. Annu Rev Nutr. 2007;27:165-77.

127. Ashkenazi A et al. The syndrome of neonatal copper deficiency. Pediatrics. 1973;52(4):525-33.

128. Cordano A. Clinical manifestations of nutritional copper deficiency in infants and children. Am J Clin Nutr. 1998;67(5 Suppl):1012S-6S.

129. Rauch $\mathrm{H}$. Toxic milk, a new mutation affecting cooper metabolism in the mouse. J Hered. 1983;74(3):141-4.

130. Lee J, Prohaska JR, Thiele DJ. Essential role for mammalian copper transporter Ctr1 in copper homeostasis and embryonic development. Proc Natl Acad Sci U S A. 2001;98(12):6842-7.

131. De Feo CJ et al. Three-dimensional structure of the human copper transporter hCTR1. Proc Natl Acad Sci U S A. 2009;106(11): 4237-42.

132. Aller SG, Unger VM. Projection structure of the human copper transporter CTR1 at 6-A resolution reveals a compact trimer with a novel channel-like architecture. Proc Natl Acad Sci U S A. 2006;103(10):3627-32.

133. Lee $J$ et al. Biochemical characterization of the human copper transporter Ctr1. J Biol Chem. 2002;277(6):4380-7.

134. Puig S et al. Biochemical and genetic analyses of yeast and human high affinity copper transporters suggest a conserved mechanism for copper uptake. J Biol Chem. 2002;277(29):26021-30.

135. Kelleher SL, Lonnerdal B. Mammary gland copper transport is stimulated by prolactin through alterations in Ctr1 and Atp7A localization. Am J Physiol Regul Integr Comp Physiol. 2006;291(4):R1181-91.

136. Kelleher SL, Lonnerdal B. Marginal maternal Zn intake in rats alters mammary gland $\mathrm{Cu}$ transporter levels and milk $\mathrm{Cu}$ concentration and affects neonatal $\mathrm{Cu}$ metabolism. J Nutr. 2003;133(7):2141-8.
137. Maryon EB, Molloy SA, Kaplan JH. Cellular glutathione plays a key role in copper uptake mediated by human copper transporter 1 . Am J Physiol Cell Physiol. 2013;304(8):C768-79.

138. Harris ED. Cellular copper transport and metabolism. Annu Rev Nutr. 2000;20:291-310.

139. Lutsenko $\mathrm{S}$ et al. Function and regulation of human coppertransporting ATPases. Physiol Rev. 2007;87(3):1011-46.

140. Ackland ML et al. Expression of menkes copper-transporting ATPase, MNK, in the lactating human breast: possible role in copper transport into milk. J Histochem Cytochem. 1999;47(12): 1553-62.

141. Michalczyk AA et al. Defective localization of the Wilson disease protein (ATP7B) in the mammary gland of the toxic milk mouse and the effects of copper supplementation. Biochem J. 2000;352(Pt 2): 565-71.

142. Buiakova OI et al. Null mutation of the murine ATP7B (Wilson disease) gene results in intracellular copper accumulation and lateonset hepatic nodular transformation. Hum Mol Genet. 1999;8(9): 1665-71.

143. Llanos RM et al. Copper transport during lactation in transgenic mice expressing the human ATP7A protein. Biochem Biophys Res Commun. 2008;372(4):613-7.

144. La Fontaine S, Mercer JF. Trafficking of the copper-ATPases, ATP7A and ATP7B: role in copper homeostasis. Arch Biochem Biophys. 2007;463(2):149-67.

145. Council NR. Nutrition during lactation. Washington, DC: The National Academies Press; 1991.

146. Endo $\mathrm{M}$ et al. Vitamin contents in rat milk and effects of dietary vitamin intakes of dams on the vitamin contents in their milk. J Nutr Sci Vitaminol (Tokyo). 2011;57(3):203-8.

147. Hediger MA et al. The ABCs of membrane transporters in health and disease (SLC series): introduction. Mol Aspects Med. 2013;34(2-3):95-107.

148. van Herwaarden $\mathrm{AE}$ et al. Multidrug transporter $\mathrm{ABCG} /$ /breast cancer resistance protein secretes riboflavin (vitamin B2) into milk. Mol Cell Biol. 2007;27(4):1247-53.

149. Jonker JW et al. The breast cancer resistance protein BCRP (ABCG2) concentrates drugs and carcinogenic xenotoxins into milk. Nat Med. 2005;11(2):127-9.

150. Yonezawa A, Inui K. Novel riboflavin transporter family RFVT/SLC52: identification, nomenclature, functional characterization and genetic diseases of RFVT/SLC52. Mol Aspects Med. 2013;34(2-3):693-701.

151. Subramanian VS et al. Role of cysteine residues in cell surface expression of the human riboflavin transporter-2 (hRFT2) in intestinal epithelial cells. Am J Physiol Gastrointest Liver Physiol. 2011;301(1):G100-9.

152. Subramanian VS et al. Differential expression of human riboflavin transporters $-1,-2$, and -3 in polarized epithelia: a key role for hRFT-2 in intestinal riboflavin uptake. Biochim Biophys Acta. 2011;1808(12):3016-21.

153. Adkins Y, Lonnerdal B. High affinity binding of the transcobalamin II-cobalamin complex and mRNA expression of haptocorrin by human mammary epithelial cells. Biochim Biophys Acta. 2001;1528(1):43-8.

154. Sandberg DP, Begley JA, Hall CA. The content, binding, and forms of vitamin B12 in milk. Am J Clin Nutr. 1981;34(9): 1717-24.

155. Zhao R, Goldman ID. Folate and thiamine transporters mediated by facilitative carriers (SLC19A1-3 and SLC46A1) and folate receptors. Mol Aspects Med. 2013;34(2-3):373-85.

156. Boulware MJ et al. Polarized expression of members of the solute carrier SLC19A gene family of water-soluble multivitamin transporters: implications for physiological function. Biochem J. 2003;376(Pt 1):43-8. 
157. Neufeld EJ et al. Thiamine-responsive megaloblastic anemia syndrome: a disorder of high-affinity thiamine transport. Blood Cells Mol Dis. 2001;27(1):135-8.

158. Sweet R, Paul A, Zastre J. Hypoxia induced upregulation and function of the thiamine transporter, SLC19A3 in a breast cancer cell line. Cancer Biol Ther. 2010;10(11):1101-11.

159. de Carvalho FD, Quick M. Surprising substrate versatility in SLC5A6: Na+-coupled I- transport by the human Na+/multivitamin transporter (hSMVT). J Biol Chem. 2011;286(1):131-7.

160. Wang $\mathrm{H}$ et al. Human placental $\mathrm{Na}+-$ dependent multivitamin transporter. Cloning, functional expression, gene structure, and chromosomal localization. J Biol Chem. 1999;274(21):14875-83.

161. Gopal E et al. Transport of nicotinate and structurally related compounds by human SMCT1 (SLC5A8) and its relevance to drug transport in the mammalian intestinal tract. Pharm Res. 2007;24(3):575-84.

162. Coady MJ et al. Establishing a definitive stoichiometry for the $\mathrm{Na}+/$ monocarboxylate cotransporter SMCT1. Biophys J. 2007;93(7): 2325-31.

163. Miyauchi S et al. Functional identification of SLC5A8, a tumor suppressor down-regulated in colon cancer, as a $\mathrm{Na}(+)$-coupled transporter for short-chain fatty acids. J Biol Chem. 2004;279(14):13293-6.

164. Biondi $C$ et al. Expression and characterization of vitamin $C$ transporter in the human trophoblast cell line HTR-8/SVneo: effect of steroids, flavonoids and NSAIDs. Mol Hum Reprod. 2007;13(1):77-83.
165. Corpe CP et al. 6-Bromo-6-deoxy-L-ascorbic acid: an ascorbate analog specific for $\mathrm{Na}+-$ dependent vitamin $\mathrm{C}$ transporter but not glucose transporter pathways. J Biol Chem. 2005;280(7):5211-20.

166. Mackenzie B, Illing AC, Hediger MA. Transport model of the human $\mathrm{Na}+-$ coupled L-ascorbic acid (vitamin C) transporter SVCT1. Am J Physiol Cell Physiol. 2008;294(2):C451-9.

167. Tsukaguchi $\mathrm{H}$ et al. A family of mammalian $\mathrm{Na}+$-dependent Lascorbic acid transporters. Nature. 1999;399(6731):70-5.

168. Zhao $\mathrm{R}$ et al. Mechanisms of membrane transport of folates into cells and across epithelia. Annu Rev Nutr. 2011;31:177-201.

169. Matherly LH, Goldman DI. Membrane transport of folates. Vitam Horm. 2003;66:403-56.

170. Borst P, Elferink RO. Mammalian $A B C$ transporters in health and disease. Annu Rev Biochem. 2002;71:537-92.

171. Ifergan I, Assaraf YG. Molecular mechanisms of adaptation to folate deficiency. Vitam Horm. 2008;79:99-143.

172. Sorensen MT et al. Cell turnover and activity in mammary tissue during lactation and the dry period in dairy cows. J Dairy Sci. 2006;89(12):4632-9.

173. Mani O et al. Differential expression and localization of lipid transporters in the bovine mammary gland during the pregnancylactation cycle. J Dairy Sci. 2009;92(8):3744-56.

174. Picciano MF. Handbook of milk composition. San Diego: Academic; 1995. 